Western Kentucky University

TopSCHOLAR®

Masters Theses \& Specialist Projects

Graduate School

Spring 2020

\title{
Morphology and Structure of Pb Thin Films Grown On Si (111) by Pulsed Laser Deposition
}

\author{
Bektur Abdisatarov \\ Western Kentucky University, bektur.abdisatarov650@topper.wku.edu
}

Follow this and additional works at: https://digitalcommons.wku.edu/theses

Part of the Engineering Science and Materials Commons, Physical Sciences and Mathematics Commons, and the Semiconductor and Optical Materials Commons

\section{Recommended Citation}

Abdisatarov, Bektur, "Morphology and Structure of Pb Thin Films Grown On Si (111) by Pulsed Laser Deposition" (2020). Masters Theses \& Specialist Projects. Paper 3178.

https://digitalcommons.wku.edu/theses/3178

This Thesis is brought to you for free and open access by TopSCHOLARß. It has been accepted for inclusion in Masters Theses \& Specialist Projects by an authorized administrator of TopSCHOLARß. For more information, please contact topscholar@wku.edu. 


\author{
A Thesis \\ Presented to \\ The Department of Physics and Astronomy \\ Western Kentucky University \\ Bowling Green, Kentucky
}

In Partial Fulfillment

Of the Requirements for the Degree

Master of Science

By

Bektur Abdisatarov

May 2020 


\section{MORPHOLOGY AND STRUCTURE OF PB THIN FILMS GROWN ON SI (111) BY PULSED}

LASER DEPOSITION

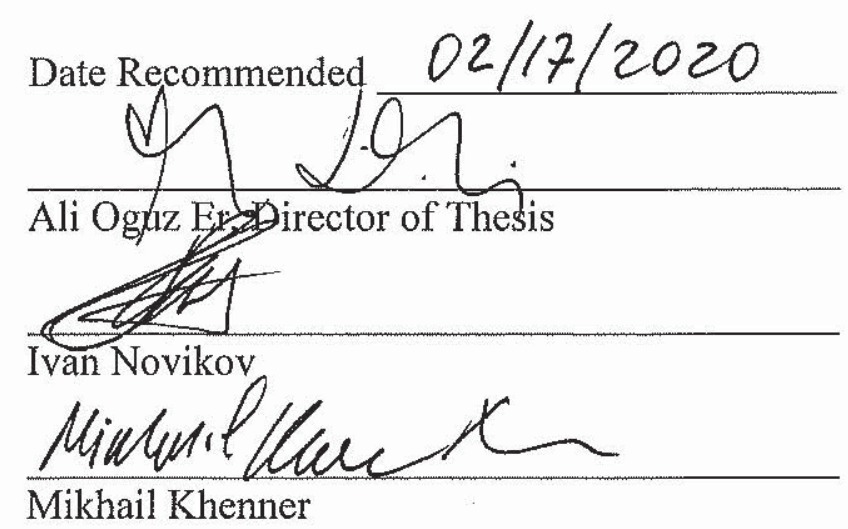

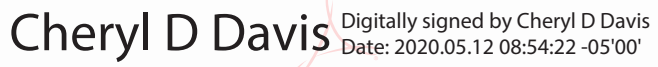

Dean, Graduate Studies and Research Date 
It would be an honor to dedicate this thesis to my family and friends. I have a unique feeling of gratitude and appreciation for my loving mother, Raikhan, for her encouragement and inspiring words that have motivated me to become a master of science. My sisters Aizat and Aiperi and my brother Bekzat gave me faith, and they were my source of strength when I was weak. All of you gave me wings that made me soar out over the open blue sky. I hope that I can make you proud, in the same way, that I am pleased to have you all as a compass for my life. I was born to make you happy. Thank you. My love for you all can never be quantified. 


\section{ACKNOWLEDGMENTS}

Firstly I would like to thank my thesis advisor Dr. Ali Oguz Er of the Physics and Astronomy department at Western Kentucky University. The door to Dr. Er's office was always open whenever I ran into a trouble spot or had a question about my research or writing. He consistently allowed this paper to be my own work but steered me in the right direction whenever he thought I needed it. I am also so grateful to Dr. Novikov and Dr. Khenner for taking their valuable time to serve on my thesis committee. Finally, I would like to say my thanks to Dr. Andersland for his pieces of training on SEM and TEM. 


\section{CONTENTS}

Chapter 1. INTRODUCTION ..............................................

Chapter 2. THEORETICAL BACKGROUND $\ldots \ldots \ldots \ldots \ldots \ldots \ldots \ldots \ldots \ldots \ldots \ldots . \ldots \ldots$

2.1 Pulsed laser deposition system.....................................6

2.2 Mechanism............................................................6

2.3 Laser-target interactions........................................

2.4 Plume expansion in a vacuum.................................. 9

2.5 Plume expansion in a background gas............................... 10

2.6 Thin film growth.............................................. 11

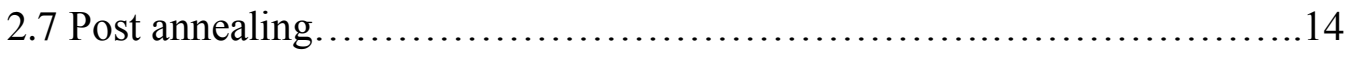

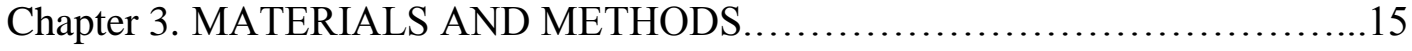

Chapter 4. RESULTS AND DISCUSSION...............................16

4.1 Surface morphology of $\mathrm{Pb}$ films....................................16

4.2 Topology of the $\mathrm{Pb}$ thin films...................................21

4.3 Crystallographic structure of $\mathrm{Pb}$ thin films...........................24

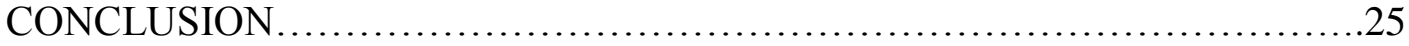

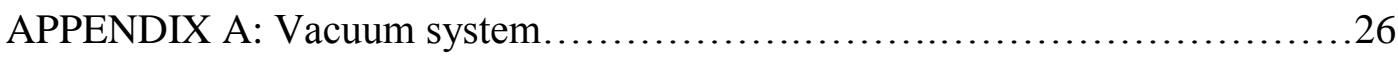

APPENDIX B: ND: YAG laser operation.....................................42

APPENDIX C: Optıcal Equipment....................................46

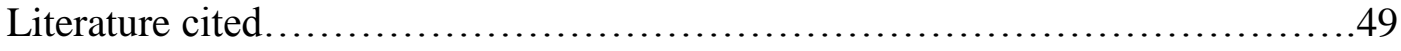


MORPHOLOGY AND STRUCTURE OF PB THIN FILMS GROWN ON SI (111) BY PULSED LASER DEPOSITION

Bektur Abdisatarov

May 2020

51 Pages

Directed by: Ali Oguz Er, Ivan Novikov, and Mikhail Khenner

Department of Physics and Astronomy Western Kentucky University

Pulsed laser deposition (PLD) is a versatile thin film deposition technique in which high powered laser beam interacts with a target material inside an ultrahigh vacuum chamber. Highly energetic particles such as electrons, atoms, protons, and ions generate a plasma plume that directed towards a substrate material where recondenses form a thin film. PLD is an effective and reliable method to create varieties of thin films such as metal, polymer, and ceramic for many technologically essential applications.

In this study, thin $\mathrm{Pb}$ films were grown by pulsed laser deposition on $\mathrm{Si}$ (111) at various laser fluences, pulse wavelengths, deposition times, and substrate temperatures. Nanosecond pulsed Nd: YAG laser with $1064 \mathrm{~nm}$ fundamental wavelength, $10 \mathrm{~Hz}$ frequency, and 5 ns pulse duration used to ablate the $99.99 \%$ pure $\mathrm{Pb}$ material. Scanning electron microscopy (SEM) and ex situ atomic force microscopy (AFM) were used to probe the surface morphology and structure. At room temperature, increasing the laser fluence and/or the pulse wavelength triggers the transformation from the "worm"-like interconnected islands to granular, separated islands. Increasing the substrate temperature to slightly below the $\mathrm{Pb}$ melting temperature results in the formation of large, nearly spherical non-wetting islands. Additionally, ultrathin $\mathrm{Pb}$ (111) films were grown at room temperature, which resulted in the appearance of a small number of almost $2 \mathrm{D}$ islands due 
to the emerging quantum size effect. Our results show that pulsed laser deposition can be used effectively for the controlled growth of $\mathrm{Pb}$ thin films. 


\section{CHAPTER 1}

\section{INTRODUCTION}

Growth of thin and ultrathin metal films has attracted considerable theoretical and experimental attention due to their interesting properties such as large lattice mismatch, thickness-dependent stability, and different chemical bonding [1-6]. Metal heteroepitaxial films are currently studied for their application in many fields, notably photovoltaics, photocathodes, optics, and plasmonics. For example, while semiconductor photocathodes have the advantage of lower work functions and higher quantum efficiencies, metallic photocathodes $(\mathrm{Cu}, \mathrm{Mg}, \mathrm{Y}$, etc. $)$ are considered as a dependable alternative [7-10] due to their shorter response time, better robustness, and longer lifetime. Quantum emission measurements of $\mathrm{Mg}$ and $\mathrm{Y}$ thin film photocathodes revealed a value of $1.8 \times 10-3$ for the Mg photocathode and 3.3 $\times 10-4$ for the $\mathrm{Y}$ photocathode [35]. However, even with these metals, the low quantum efficiency of a metal used in superconducting cavities, such as niobium, is still a problem [11-13]. The photoemission performance of those cavities could be improved by using photocathodes made from other metals or metal alloys.

$\mathrm{Pb}$ (lead) thin films are of particular interest for photocathode applications in superconducting radiofrequency guns, solid lubricants, and aerospace and junction electrode applications [7]. Lead has a critical temperature $7.2 \mathrm{~K}$, which is close to that of niobium $(9.3 \mathrm{~K})$, and it has higher quantum efficiency (around 7.5 x10-5 at $250 \mathrm{~nm}$ vs. niobium quantum efficiency of $1 \times 10-5$ at $250 \mathrm{~nm}$ ) [10,34].

Many techniques have been used for growth of $\mathrm{Pb}$ thin films for photocathode applications, such as electroplated deposition, arc deposition, sputtering, evaporation and pulsed laser deposition (PLD) [9-19]. The formation of thin films with different 
morphology and crystalline structure is of utmost importance for the development in those applications, and there are ongoing experimental investigations into the characterization of these morphologies [7].

PLD is a thin film deposition technique where a high-power pulsed laser beam is focused inside the vacuum chamber to ablate the target of the desired composition. Parallel to developments in lasers, PLD has become very popular. PLD was the first technique used to deposit a superconducting $\mathrm{YBa} 2 \mathrm{Cu} 3 \mathrm{O} 7$ thin film [20]. Since that time, PLD was used to grow high-quality films of superconductors [17,21,22], magneto-resistant materials [23], semiconductors [24], ferroelectrics, and many others [29].

A well-known drawback of PLD is the emergence of particulates during deposition [16,19,25-28]. These droplets could degrade the photoemission performance of photocathodes. The droplet size varies from sub-micron to several micrometers, and particulates formation is affected by several parameters such as the target material, surface quality, and laser energy density [16,19]. Pb thin films were previously deposited on $\mathrm{Nb}$ substrates using ultrafast laser pulses. Granular films with a maximum quantum efficiency of $7.3 \times 10-5$ at laser wavelength $266 \mathrm{~nm}$ and 7 nanosecond pulse duration were obtained [18]. In this work, we deposited $\mathrm{Pb}$ thin films of varying thickness at substrate temperatures $25^{\circ} \mathrm{C}-300^{\circ} \mathrm{C}$ and using different laser wavelengths and laser energy density (fluence). Our results demonstrate that $\mathrm{Pb}$ thin films can be reliably grown by PLD, and their morphology is strongly dependent on these parameters. 


\section{CHAPTER 2}

\section{THEORETICAL BACKGROUND}

\subsection{Pulsed laser deposition system}

Pulsed laser deposition (PLD) is one of the versatile deposition technique that uses a pulsed laser source to ablate the target material. High powered laser beam interacts with bulk material; as a result, bulk material will be removed. Ablated target material generates plasma plum that contains highly energetic particles such as electrons, protons, ions, and atoms. These particles directed toward the substrate material where recondenses form a thin film. All these processes occur in an ultra-high vacuum chamber. The basic structure of the PLD system is shown in Figure 1.

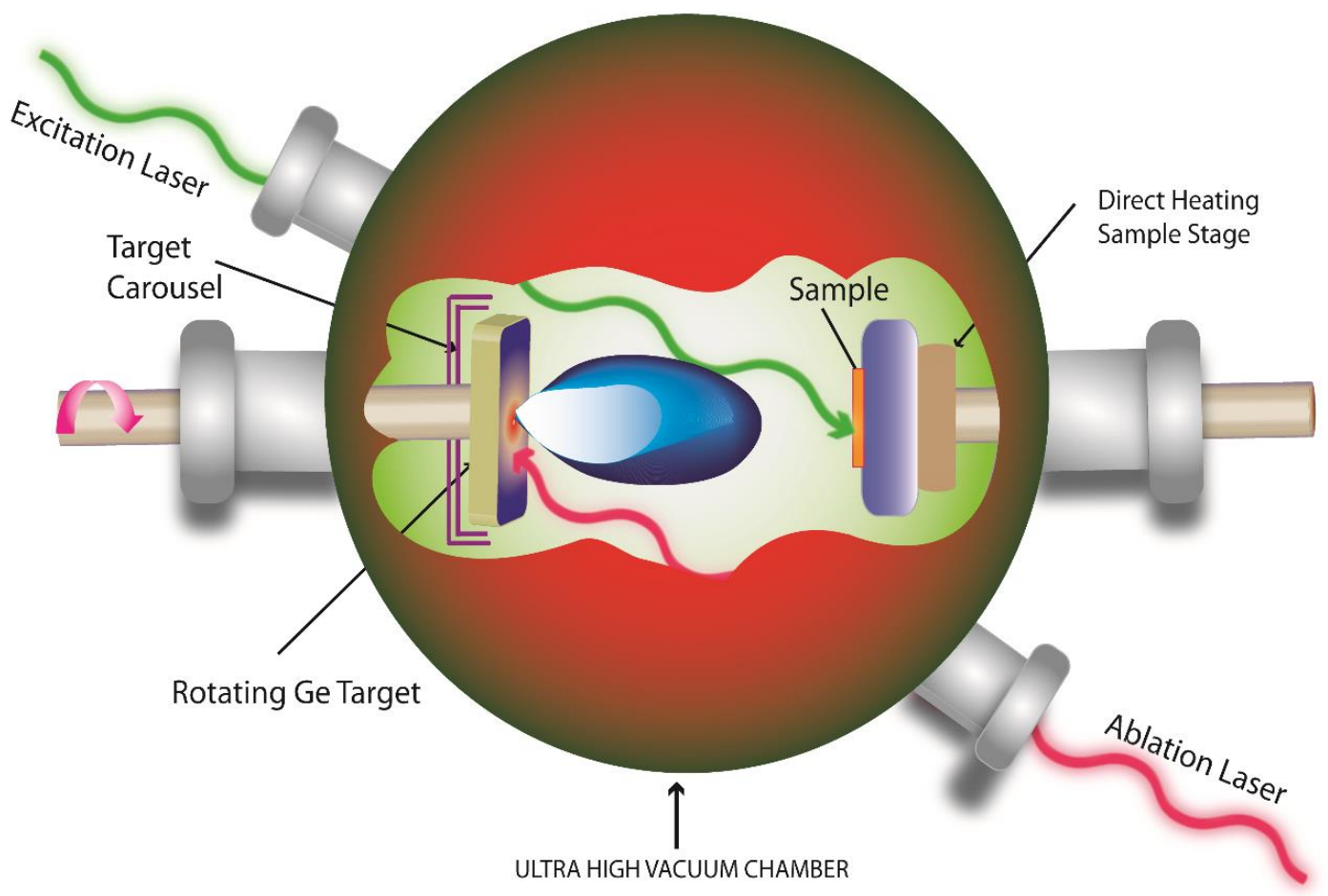

Figure 1. Basic structure of pulsed laser deposition 
The PLD setup consists of high powered laser source and optical instruments to control the beam, ultra-high vacuum chamber, target material, and substrate. Target and substrate are fixed perpendicular to each other inside the vacuum chamber, which can be evacuated by the vacuum pumps.

Initially, this method was used for maintaining the stoichiometry of complicated chemical structures, in the mid-60th researchers realized that laser power could be used in the growth and control of nanometer and micrometer-sized structures [4-5]. After hightemperature superconductor $\mathrm{YBa}_{2} \mathrm{Cu}_{3} \mathrm{O}_{7}$ created in 1987 with the laser deposition system, this system became more popular and attractive in a wide range of research areas from superconductivity, to electrocatalysis or electrochemistry [2-4].

Parallel to developments in lasers, and other researches pulsed laser deposition system has been developed. One of the most important developments from the conventional method is to use reactive background gases such as oxygen, argon, and nitrogen. It provides a higher pressure during the interactions, yet to maintain a defined and low background pressure. The reactive gas and plasma plume ablated from target material interact with each other, which results in a strong degree of scattering between the gas and the plume species. These two beams merge and directed towards together almost collision-free while maintaining their reactivity for the film growth. As a result, surface morphology can be improved.

The main advantages of pulsed laser deposition technique are:

The laser and other important equipment located outside of the vacuum chamber. Therefore, all important parameters can be controlled from outside. 
The system is flexible and easy to implement. Any material or material combination can be ablated by adjusting laser wavelength and laser fluence.

The growth rate of the thin film can be precisely controlled because of the pulsed laser beam.

The pulsed laser deposition technique provides exactly stoichiometry transfer of any complex target composition.

The system is cost-effective. One laser can serve many depositions and vacuum system.

$>$ Resonant interactions possible

There are several disadvantages of pulsed laser deposition. These disadvantages are not only come from technical nature but also intrinsic to the ablation process and the electromagnetic interaction between photons and materials.

$>$ The high kinetic energy of some particles in plasma plume causes resputtering. As a result, defects can occur both on the substrate surface and the growing thin film.

$>$ Distribution of laser energy may not be homogeneous, which causes inhomogeneous energy profile and angular energy distribution in the plasma plume.

The weight of the elements, such as oxygen, is lighter than heavy metal elements. This difference causes different expansion velocities and angular distribution in a plasma plume. Desired background gas needed to prevent this problem. 
Micrometer sized particles from the target can be ejected during the ablation due to the high laser energy and decrease index of homogeneity of the deposited thin film.

$>$ Pulsed laser deposition technique is not suitable for a large area.

The exact growth mechanism of the thin film is still not clear. Scientists are still trying to understand the mechanism and doing researches to figure out.

\subsection{Mechanism}

The growth kinetics of thin films depends on the laser power and wavelength, absorption properties of the target material, substrate material and its temperature, pressure in a vacuum chamber, and background gas. During the irradiation, part of the laser power converts into the heat, and the surface of the target melts or vaporizes promptly. The liquid surface splashes by the shockwave and liquid droplets release with supersonic speeds. Droplets condense on the surface of the substrate material. All these processes presented step by step in Figure 2 . 


(a) -Absorption $\left[\mathrm{I}=\mathrm{I}_{0} \exp (-\mathrm{ax})\right]$
-Thermal conduction
(b) -Surface melting
(c) -Vaporization
-Thermo-ionic emission
-Absorption of radiation/evaporated material:
Inverse-bremmstrahlung effect
$\rightarrow$ Plasma formation and expansion
-Auto-regulation of Temperature of plasma
-Condensation on substrate, film growth

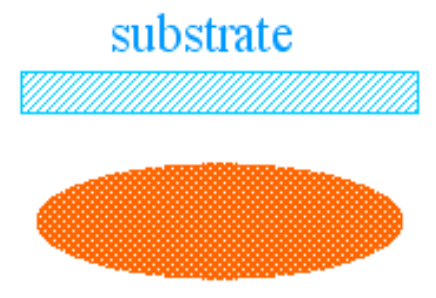

(e)

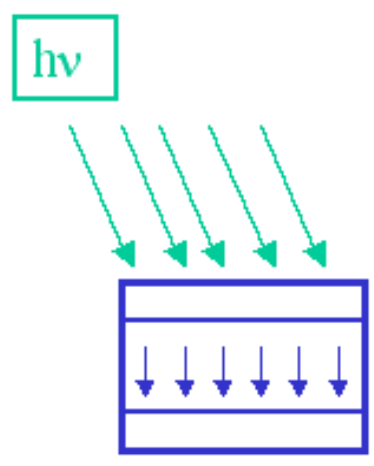

(a)

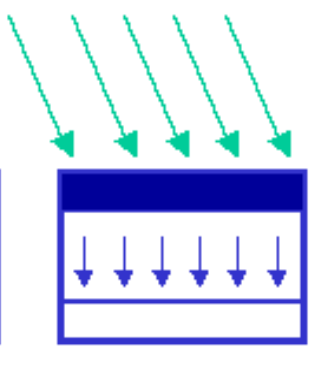

(b)

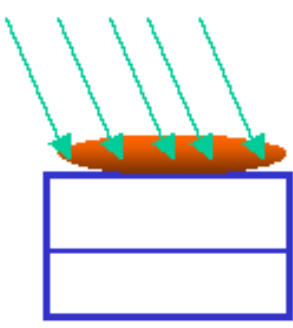

(c)

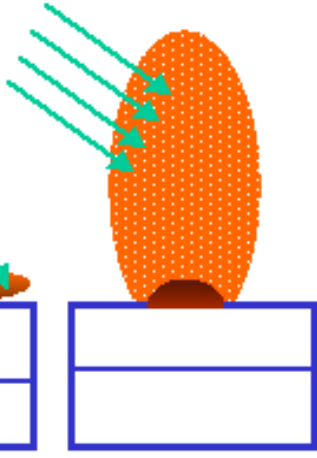

(d)

\section{PULSE DURATION}

Figure 2. Mechanism of ablation and deposition

\subsection{Laser-target interaction}

When the laser light interacts with bulk material, a percentage of this laser energy is absorbed into the material while the rest is reflected. If the amount of the energy absorbed by the material sufficient enough to break the chemical bonds holding the material together, then the ablation threshold has been surpassed. Electronic relaxation lifetime is very short, and it is $10^{-14}-10^{-13} \mathrm{~s}$ for metals, and it varies between $10^{-12} \mathrm{~s}$ and $10^{-3} \mathrm{~s}$ for nonmetals. The time scale depends on specific heat, thermal conductivity, and electron-phonon coupling properties. Laser radiation is absorbed in the form of inverse Bremsstrahlung absorptivity property $\alpha$ of the target material which is given by equation: 


$$
\alpha=3.7 * 10^{8} \frac{Z^{3} \rho_{i}^{2}}{v^{3} \sqrt{T}}\left(1-e^{-\frac{h v}{k T}}\right)
$$

where $Z=1$ is an elementary charge of the ion, $\rho_{i}$ is the density of singly charged ions in $\mathrm{cm}^{3}, T$ is the gas temperature in Kelvins, $v$ is the frequency of radiation in $\mathrm{Hz}, h$ is Planck's constant, and $k$ is Boltzmann's constant. Skin depth is the distance at which laser energy penetrates the material and depends on the material's optical properties and laser wavelength. The skin depth $\delta$ is given by the following equation:

$$
\delta=\sqrt{\frac{2}{\omega \mu \sigma}}
$$

where $\omega$ is the angular frequency of the radiated light, $\mu$ is the magnetic permeability, and $\sigma$ is its conductivity of the material. Electrons located in the skin depth layer become higher energy state and subsequently heat, melt, and vaporize. The heat penetration depth $D$, given by the following equation:

$$
D=\sqrt{\frac{2 k \tau_{p}}{\rho c}}
$$

where $\tau_{p}$ the pulse width of the laser, $k$ is the thermal conductivity, $\rho$ is the mass density of the material, and $c$ is the speed of the light. The ablation depth $\Delta z$ is given by

$$
\Delta z \approx \frac{A\left(F_{L}-F_{t}\right)}{\rho L_{v}}
$$

where $A$ is the surface absorbance, $F_{L}$ is the laser fluence, $F_{t}$ is the laser fluence threshold representing the minimum energy which desired vaporization occurs, and $L_{v}$ is the latent heat per unit mass. [30-35]

Two dominant mechanisms, inverse Bremsstrahlung, and potentization, are involved in the plasma plume when nanosecond pulsed laser used to irradiate the target 
material. Because there is enough time for the thermal wave to penetrate into the material, which causes the melting and evaporation process. Using this type of lasers causes the direct ejection of the droplets from target material that may be embedded in a thin film. Since this phenomena induce vapor ionization and excitation through collisions with ground and excited state neutrals.

\subsection{Plume expansion in a vacuum}

Ablated highly energetic particles generate a plasma plume directed towards substrate material. The expansion of the plume can be characterized by ellipsoid shape according to the Anisimov simulation and model. (10)

There are some reports that laser impact on the plume expansion can be separated into two regions over the plume evolution time. The first one is an isothermal expansion. This expansion occurs during the pulse duration and can be modeled by the following expression:

$$
X(t)\left(\frac{1}{t} \frac{d X}{d t}+\frac{d^{2} X}{d t^{2}}\right)=Y(t)\left(\frac{1}{t} \frac{d Y}{d t}+\frac{d^{2} Y}{d t^{2}}\right)=Z(t)\left(\frac{1}{t} \frac{d Z}{d t}+\frac{d^{2} Z}{d t^{2}}\right)=\frac{k_{B} T}{m}, t \leq \tau
$$

where $m$ is the mass of the particles, and $X(t), Y(t)$, and $Z(t)$ terms denote the dimensions for plasma expansion as a function of time along with the 3-dimensional $\mathrm{x}-, \mathrm{y}-$, and $\mathrm{z}$ axes.

The second region is called adiabatic expansion which occurs beginning at the termination of the laser pulse. The expression for this can be given by the following:

$$
X(t)\left(\frac{d^{2} X}{d t^{2}}\right)=Y(t)\left(\frac{d^{2} Y}{d t^{2}}\right)=Z(t)\left(\frac{d^{2} Z}{d t^{2}}\right)=\frac{k_{B} T}{m}\left(\frac{X_{0} Y_{0} Z_{0}}{X(t) Y(t) Z(t)}\right)^{\gamma-1}, t>\tau
$$


where $X_{0}, Y_{0}$, and $Z_{0}$ are the initial orthogonal edges of the plasma after the termination of the laser pulse $(t=\tau)$ and $Y$ is the ratio of the specific heat capacities at constant pressure and volume. (6-7-8)

In nanosecond pulsed laser irradiation, the ablation rate can exceed 0.1 monolayers per second. At the target surface, the highest particle densities are formed. Multiple scattering between highly energetic particles tends to equilibrate the plasma thermally, and this formation called the Knudsen layer, which modifies the Maxwell- Boltzmann distribution.

$$
f(v)=A\left(\frac{m}{2 \pi k}\right)^{\frac{3}{2}} v^{n} e^{\left(\frac{-m(v-u)^{2}}{2 k T}\right) d v}
$$

where $m$ is the mass of the particles, $k$ is the Boltzmann constant, $v$ is the speed along the propagation direction, $u$ is the stream velocity, $T$ is the stream speed, which describes the angular distribution of the propagation, and $n$ is an integer typically 3-4 [30-35].

\subsection{Plume expansion in a background gas}

Background gas is used to reduce the kinetic energy of the plasma plume particles and increase the reactivity of the plume with gas to form atomic and diatomic molecules. The expansion of the plume into a background gas is still not clear and not well understood. If the pressure less than $1 \mathrm{~Pa}$, the expansion of the plasma is similar to the expansion in a vacuum. Beyond that, the shock wave is formed at the surface and pushes the background gas. 
If the mean free path of the plasma is shortened, the plume pressure equalizes the background pressure. Zeldovich and Raizer have been modeled the plume mass by the following expression:

$$
M_{p} \approx \frac{2}{3} \pi R^{3} \rho_{g}
$$

where $R$ is the distance at which the shock wave starts, and $\rho_{g}$ is the gas density. The spherical expansion of the plasma plume into background gas can be modeled with a blast wave model as a function of the time:

$$
R(t)=\varepsilon_{0}\left(\frac{2 E_{0}}{\rho_{g}}\right)^{\frac{1}{5}} t^{\frac{2}{5}}
$$

where $\varepsilon_{0}$ and $\rho_{g}$ are constants calculated by the specific heat ratio and the mass density of the layer. [30-35]

\subsection{Thin film growth}

Thin film growth is not a trivial process and depends on a number of factors, including density, energy, ionization degree, target material, substrate, pressure, temperature, and other environmental conditions.

The substrate material's properties are very important for the best thin film growth. In many applications, the epitaxial growth of material is preferred. The main requirement is a good crystallographic lattice match between thin film and substrate. Therefore, the substrate material should be chemically compatible with the thin film. Moreover, when we choose substrate material, we should pay attention to the thermal expansion coefficients, and material should thermodynamically and chemically stable surface. 
The basic order of the thin film growth process can be explained in four steps, chemisorption and physisorption, condensation, surface diffusion, and nucleation. If compatible substrate material is chosen according to is the explanation above. (Figure 3)

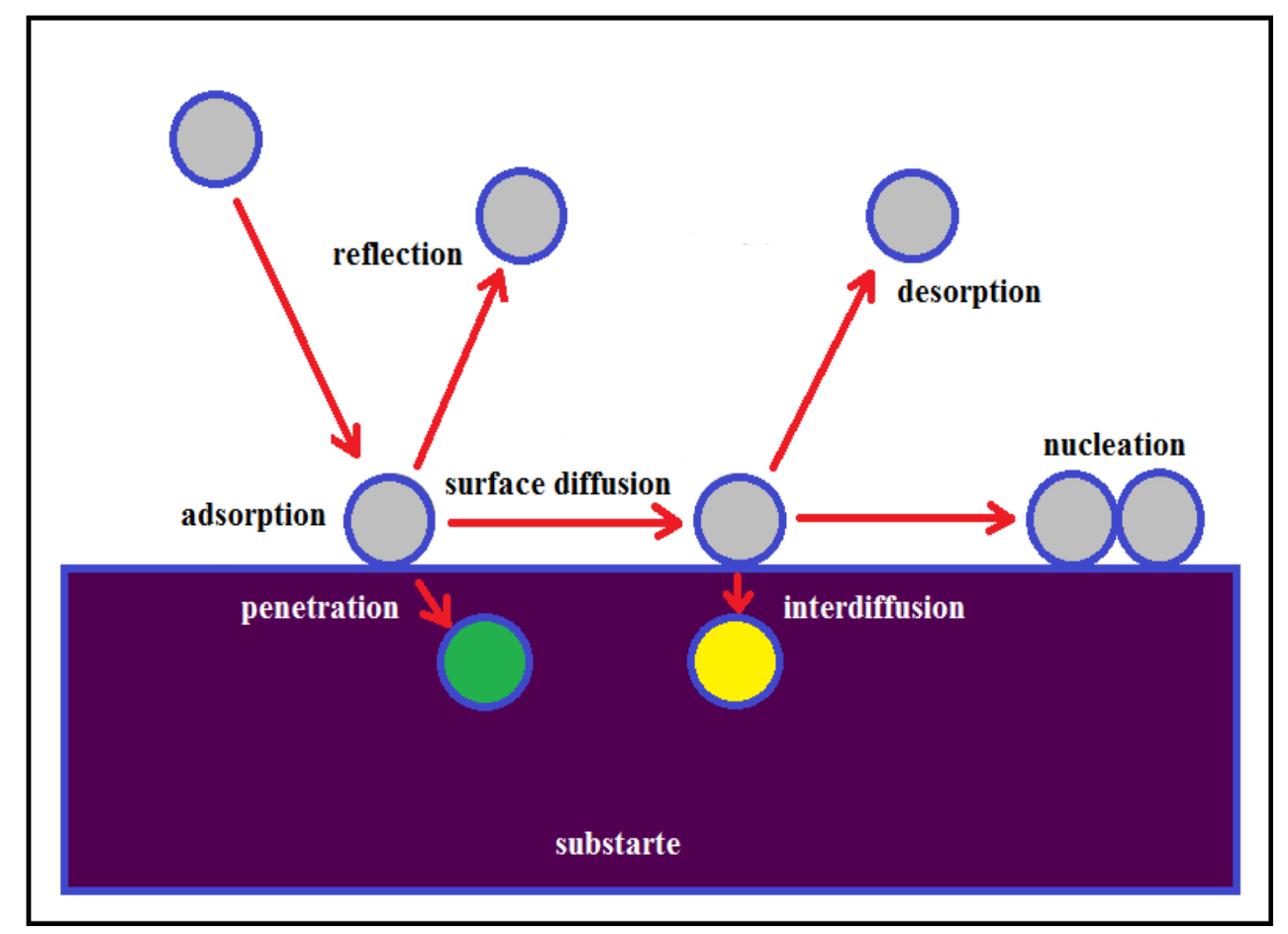

Figure 3. Thin film growth process.

The temperature of the substrate and thermodynamic driving force are the main parameters in film growth. The following equation can calculate thermodynamic driving force $\Delta \mu$ :

$$
\Delta \mu=k T \ln \left(\frac{R}{R_{e}}\right)
$$

where $k$ is Boltzmann constant, $R$ is deposition rate of the film, and $R_{e}$ is an equilibrium value at temperature $T$. The thermodynamic driving force is positive in the condensation process, it is negative in the evaporation process, and it is zero in an equilibrium situation. Thin film deposition rate can be calculated by the following equation: 


$$
R=\frac{\beta P}{\sqrt{2 \pi m k T}}
$$

where $P$ is vapor pressure at the substrate surface, $\beta$ is the proportionality factor, $m$ is an atomic or molecular mass, and $T$ is the temperature. The residence time in particles coming from plasma plume absorbed on the surface is a function of adsorption energy. In this period, adatoms diffuse over the surface of the substrate with diffusion energy.

One of the most important processes in thin film growth is surface diffusion of the adatoms. The kinetic energy and angular distribution of ablated species are the main parameters for surface diffusion. The energy of the particles allows finding each other on the surface of the substrate for epitaxial growth. During the diffusion, temperature plays a significant role as well as surface diffusion coefficient. For the surface diffusion process, adatoms need a certain amount of energy. If the kinetic energy of the adatoms is not enough for the surface diffusion substrate can be heated up from outside to increase the energy of the particle with heat energy. [30-35]

There are three types of film growth modes, which are presented in figure 4; Volmer-Weber type nucleation and formation of three-dimensional islands, Frank-van der Merwe type two dimensional layer by layer growth, and Stranski-Krastanov type layer by layer growth followed by the formation of three-dimensional islands. 


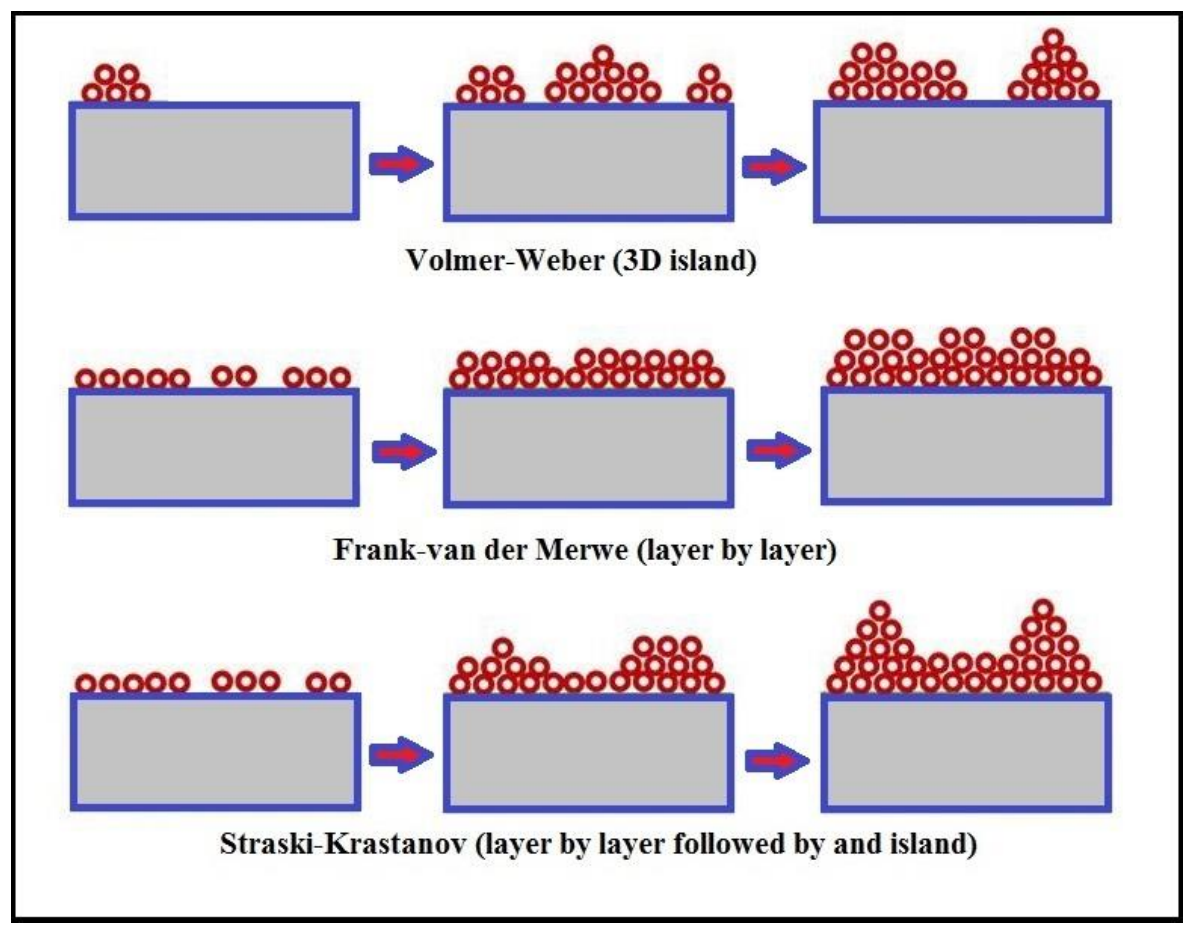

Figure 4. Schematic illustrating three modes of film growth.

\subsection{Post annealing}

The post-annealing process is used to crystallize the deposited amorphous material. However, heating may cause phase transition and alters the structure and morphology through Ostwald ripening and thermal stress diffusion. Moreover, nanometer or micrometer size cracks can be observed because of thermal stress. Depending on annealing temperature and duration, the average grain size increases. The annealing in air ambient can also create oxygen vacancies that improve the sensitivity of the thin film for gases.[30-35] 


\section{CHAPTER 3}

\section{MATERIALS AND METHODS}

Nanosecond Q-switched Nd: YAG Continuum Surelite II pulsed laser was used as the irradiation source. The laser has a fundamental wavelength of $1064 \mathrm{~nm}$, the pulse width of 5 nanoseconds, $10 \mathrm{~Hz}$ repetition rate, and the Gaussian pulse shape with $6 \mathrm{~mm}$ diameter of the unfocused beam. Moreover, frequency reduced the second harmonics of the laser (532 nm wavelength) was also used. The experimental setup for the PLD system in our lab is shown in Figure 1. For the ablation target, a $99.99 \%$ purity $\mathrm{Pb}$ source (MTI Corp.) was used. The laser beam was focused to a spot size of $1 \mathrm{~mm}$ and was incident at an angle of $45^{\circ}$ on the target. The target was rotated at $5 \mathrm{rpm}$ to ensure the homogeneous consumption of target material during the ablation process. For the deposition, N-type doped Si (111) substrates (MTI Corp.) with natural oxide layer were used as-received, without any additional surface cleaning processes, to collect the ablated species. The base pressure was initially reduced to mid-10-8 torr using three different pumps; rotary, turbomolecular, and ion-sputtering. Laser fluences of 2, 4, and $8 \mathrm{~J} / \mathrm{cm} 2$ were used. Laser fluence was adjusted by variable beam attenuator utilizing a pair of half-wave plate and polarizer. Laser q-switch and spot size were not changed.

For the films obtained at $8 \mathrm{~J} / \mathrm{cm} 2$ laser fluence, the effects of deposition time and substrate temperature were investigated. The substrate temperature was set at 25, 75, 150, and $300{ }^{\circ} \mathrm{C}$. The substrate to target distance was set to $3 \mathrm{~cm}$. The deposition was performed at irradiation times of 40, 60, 120, 240, 480, 600 seconds. Scanning electron microscopy (SEM, Jeol 6510LV) was utilized to characterize the surface morphology and the crosssectional thickness of the as-deposited thin films. Atomic force microscopy (AFM, 
Agilent 5500) was used to analyze the topography and thickness of the films. X-ray diffraction (XRD) was used to investigate the structure and crystallographic orientation of the films.

\section{CHAPTER 4}

\section{RESULTS AND DISCUSSIONS}

\subsection{Surface morphology of $\mathrm{Pb}$ films}

By using SEM to characterize the films after growth at $25^{\circ} \mathrm{C}$, it was found that when the low laser fluence of $2 \mathrm{~J} / \mathrm{cm}^{2}$ was used to irradiate the target, the thin films displayed a 'worm'-like nanoisland structure as shown in Figure 5(a). Further increasing the laser fluence to 4 and $8 \mathrm{~J} / \mathrm{cm}^{2}$ resulted in the formation of a granular nanostructure, as seen in Figure 2(b, c).
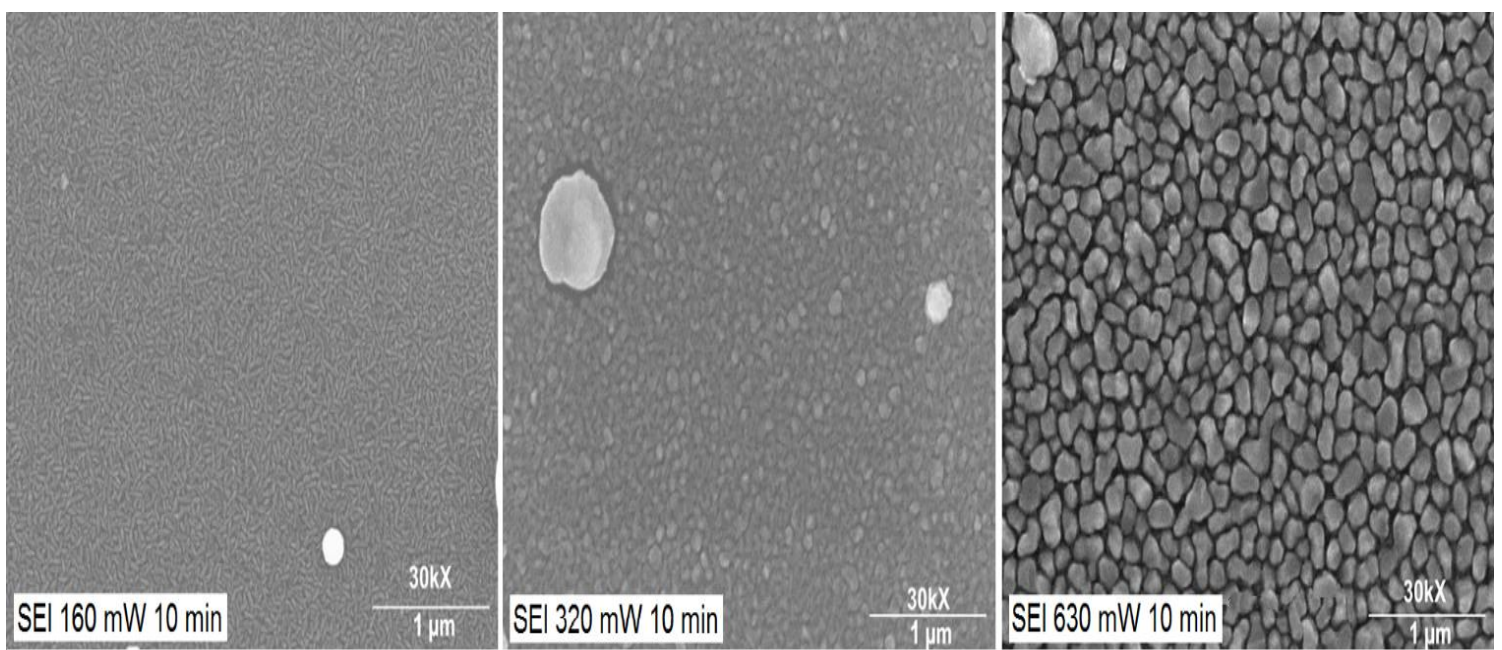

Figure 5. SEM images of $\mathrm{Pb}$ thin films deposited for 600 seconds at $25^{\circ} \mathrm{C}$, laser wavelength $1064 \mathrm{~nm}$ and laser fluence of (a) $2 \mathrm{~J} / \mathrm{cm}^{2}$, (b) $4 \mathrm{~J} / \mathrm{cm}^{2}$, and (c) $8 \mathrm{~J} / \mathrm{cm}^{2}$. 
Next, the effects of $1064 \mathrm{~nm}$ and $532 \mathrm{~nm}$ laser wavelength were investigated for the laser fluence of $8 \mathrm{~J} / \mathrm{cm}^{2}$. Figure 6 shows the SEM micrographs of $\mathrm{Pb}$ films in the order of increasing target irradiation time for both wavelengths.

From Figure 6(a) and 6(f), it can be seen that after 40 seconds of film deposition, the films exhibit similar 'worm'-like nanostructure. However, after 120 seconds of film deposition, the morphology of the films produced by $1064 \mathrm{~nm}$ wavelength becomes granular, while the one produced by $532 \mathrm{~nm}$ wavelength still preserves the 'worm'-like structure (Figures 6(b) and 6(g)). At $532 \mathrm{~nm}$ wavelength, further increase of the deposition time results in thin films with co-existing granular and 'worm'-like structures, but using $1064 \mathrm{~nm}$ wavelength produces only granular thin films, see Figures 6(c-e) and 6(h-j), respectively. Notice that the size of the granules increases with the growth time.
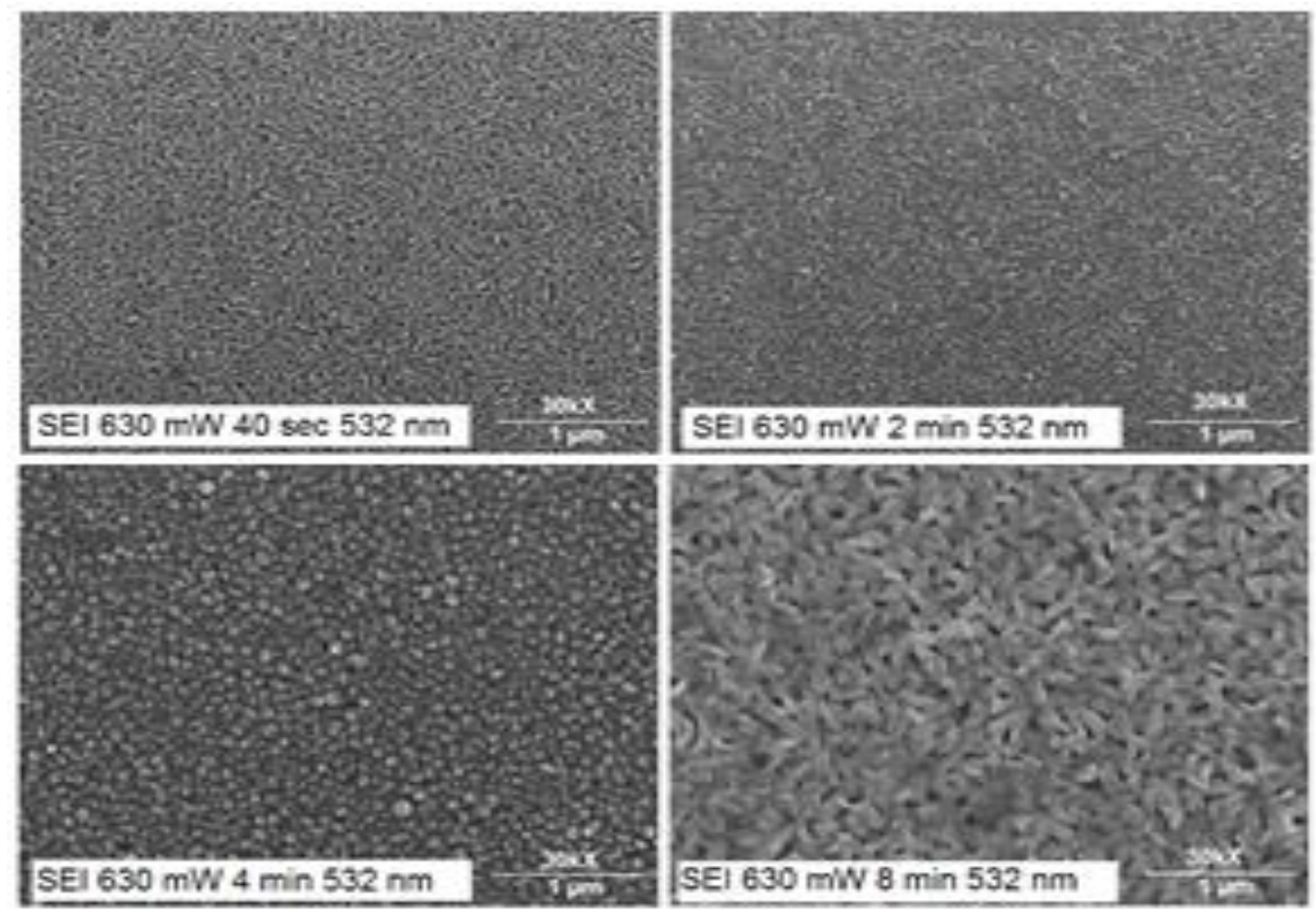

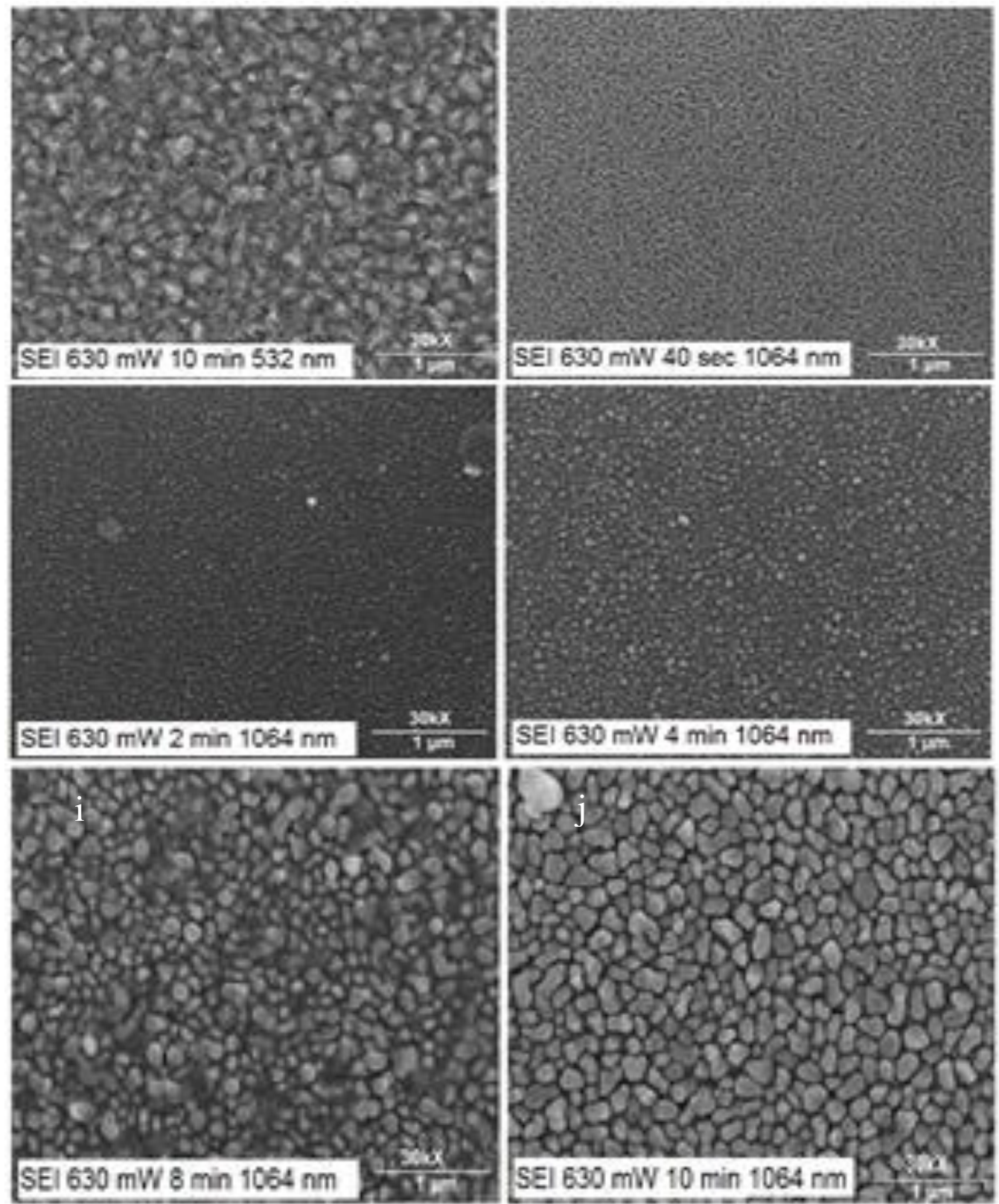

Figure 6. (a-e): $\mathrm{SEM}$ images of $\mathrm{Pb}$ films deposited at $25^{\circ} \mathrm{C}$ using laser wavelength 532 $\mathrm{nm}$ and laser fluence $8 \mathrm{~J} / \mathrm{cm}^{2}$, for (a) $40 \mathrm{~s}$ (b) $120 \mathrm{~s}$ (c) $240 \mathrm{~s} \mathrm{(d)} 480 \mathrm{~s} \mathrm{(e)} 600 \mathrm{~s}$. (f-j): Same parameters as for (a-e), except the wavelength is $1064 \mathrm{~nm}$; (f) $40 \mathrm{~s} \mathrm{(g)} 120 \mathrm{~s}$ (h) $240 \mathrm{~s} \mathrm{(i)} 480 \mathrm{~s}(\mathrm{j}) 600 \mathrm{~s}$.

The thickness of the films was measured by cutting the deposited sample and checking the cross-section in the SEM. Figure 7 is the SEM cross-section micrograph in 
the backscattered electron composition (BEC) imaging mode for $\mathrm{Pb}$ thin film deposited for 600 seconds at $25^{\circ} \mathrm{C}$, laser wavelength $1064 \mathrm{~nm}$, and laser fluence $8 \mathrm{~J} / \mathrm{cm}^{2}$.

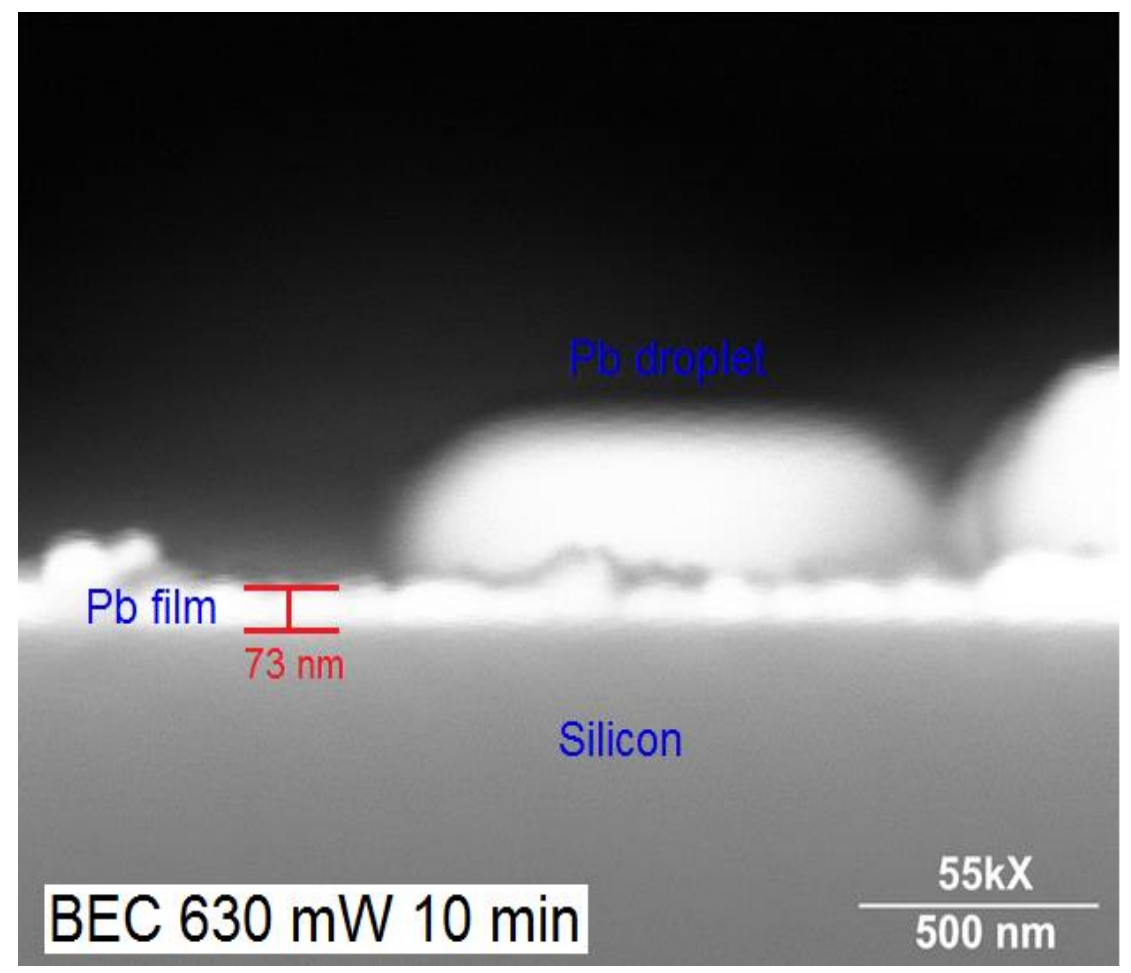

Figure 7. Cross-section SEM image of Pb thin film in Figure 5(c) (and Figure 6(j)).

The film thickness is around $73 \mathrm{~nm}$. Moreover, micrometer size droplets due to the direct ejection of the melted material from the $\mathrm{Pb}$ target during the laser ablation can be seen. The growth of lead films was also carried out at various substrate temperatures. Figure 8 shows the $\mathrm{SEM}$ images of $\mathrm{Pb}$ films obtained at $25,75,150$, and $300^{\circ} \mathrm{C}$. At room temperature, the film displays an interconnected grain-like structure, see Figure 8(a) (or Figure 6(h)). Initially, the film grows in a Vollmer-Weber mode, i.e., by the formation of three-dimensional islands. 
Increasing the substrate temperature promotes the formation of non-wetting clusters [10], which becomes noticeable at $75^{\circ} \mathrm{C}$ and $150^{\circ} \mathrm{C}$, see Figures $8(\mathrm{~b}, \mathrm{c})$. Further increasing the temperature to $300{ }^{\circ} \mathrm{C}$, which is close to the melting temperature of $\mathrm{Pb}(327$ $\left.{ }^{\circ} \mathrm{C}\right)$, results in the film agglomeration into larger spherical islands, as seen in Figure $8(\mathrm{~d})$. This is likely due to accelerated Ostwald ripening.
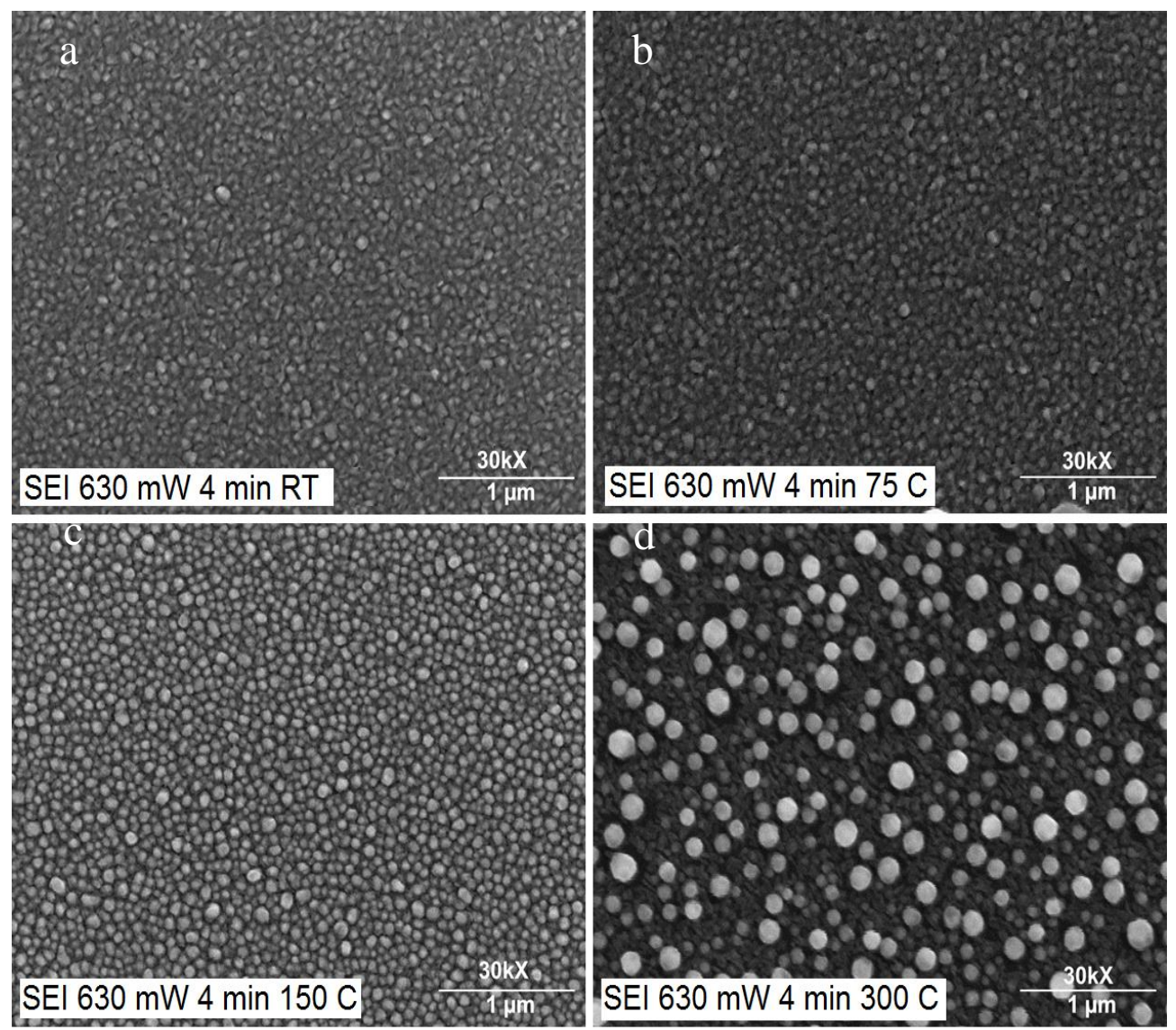

Figure 8. SEM images of $\mathrm{Pb}$ films deposited for $240 \mathrm{~s}$ using laser wavelength $1064 \mathrm{~nm}$ and laser fluence $8 \mathrm{~J} / \mathrm{cm}^{2}$, at (a) $25^{\circ} \mathrm{C}$ (b) $75^{\circ} \mathrm{C}$ (c) $150^{\circ} \mathrm{C}$, and (d) $300^{\circ} \mathrm{C}$. 


\subsection{Topology of the $\mathrm{Pb}$ thin films}

The surface morphology of the film in Figure 8(a) was also analyzed by AFM. Extracting the height profile along the line drawn on intensity AFM micrograph in Figure 9(a) shows that the surface of the thin film is composed of 40-50 $\mathrm{nm}$ high nanoislands, see Figure 9(b).
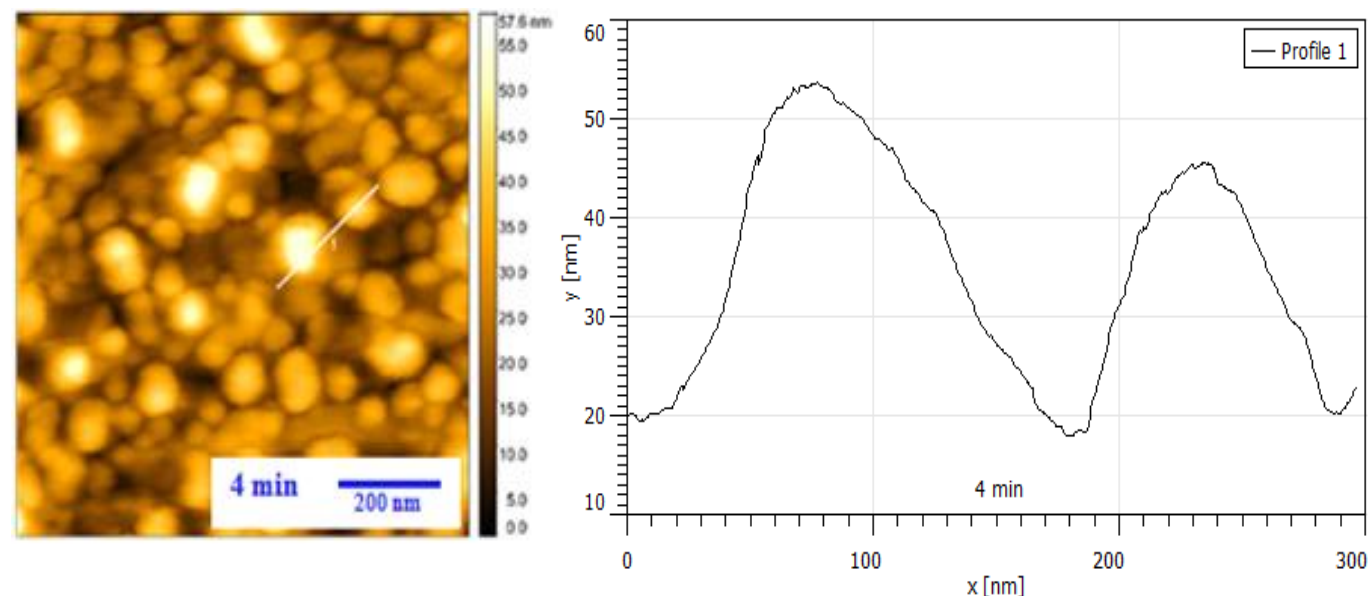

Figure 9. (a) AFM image of the surface morphology of $\mathrm{Pb}$ film deposited at $25^{\circ} \mathrm{C}$ for $240 \mathrm{~s}$ using laser wavelength $1064 \mathrm{~nm}$ and laser fluence $8 \mathrm{~J} / \mathrm{cm}^{2}$, and (b) the height profiles along the line drawn on intensity AFM micrograph in (a).

We also carried out the depositions at $25^{\circ} \mathrm{C}$ and the laser parameters as in Figures 8(a) and 9(a), but for shorter times (20 s and $10 \mathrm{~s})$. Figures 10 and 11 show the resultant islands at high magnification. The height profiles of a few randomly chosen islands show that these islands have the maximum height around $13 \mathrm{~nm}$ for $20 \mathrm{~s}$ deposition and $4 \mathrm{~nm}$ for 10 s deposition. 

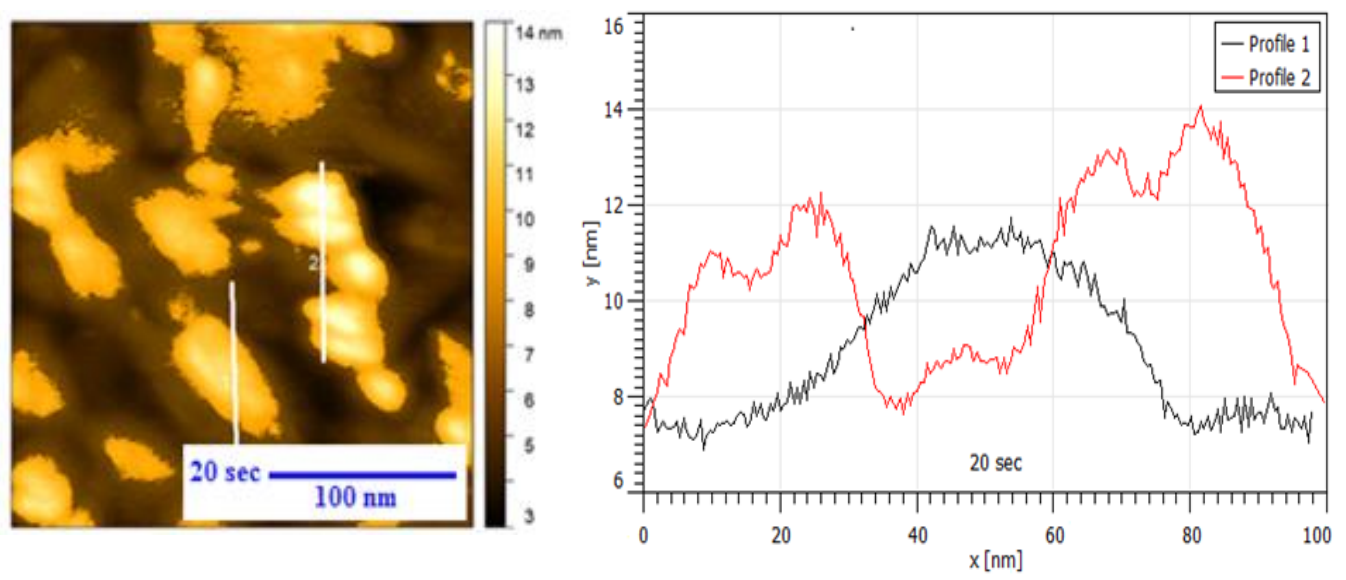

Figure 10. (a) AFM image of the surface morphology of $\mathrm{Pb}$ film deposited at $25^{\circ} \mathrm{C}$ for $20 \mathrm{~s}$ using laser wavelength $1064 \mathrm{~nm}$ and laser fluence $8 \mathrm{~J} / \mathrm{cm}^{2}$, and (b) the height profiles along the lines drawn on intensity AFM micrograph in (a).

Also, we notice in Figure 10 that the islands start to develop the large and horizontal mesa-like top surface. At $10 \mathrm{~s}$ deposition (Figure 11), the large mesa is fully developed. Notice that the mesa extends over the distance that is more than fifteen times the height of the island, and the height variation along the mesa middle section does not exceed $0.2-0.3 \mathrm{~nm}$ (1 ML of Pb is equivalent to $0.284 \mathrm{~nm}$ ). Such nearly flat (nearly atomically smooth) island morphology is the signature of the emerging quantum size effect (QSE), which at lower temperatures (100-200K) results in mostly 2D islands [3-5] with an exactly atomically smooth surface. The island heights in Figure 11(b) are, with high accuracy, $2.8 \mathrm{~nm}(10 \mathrm{ML})$ and $3.9 \mathrm{~nm}$ (14 ML). This count includes Pb wetting layer (1ML), thus $0 \mathrm{ML}$ refers to the $\mathrm{Si}$ surface. These so-called "magic" heights were observed in the experiments on low-temperature quantum island growth in $\mathrm{Pb} / \mathrm{Si}(111)$ system [3-5]; also, they were predicted by the Density Functional Theory and Electron Gas Model computations [6]. 
Another signature of QSE is the film height at the island base. In Fig. 10(b), this height is $7 \mathrm{~nm}$, or 25ML, whereas in Fig. 11(b) this height is between 1.7 and $2 \mathrm{~nm}$ (6 or $7 \mathrm{ML}$ ) or around $1 \mathrm{~nm}$ (4 ML). 4, 6, and $25 \mathrm{ML}$ also are the magic heights in $\mathrm{Pb} / \mathrm{Si}(111)$ system [3]. (The origin of the magic heights lies in the quantization of the electronic energy in the direction across the metal film. The electronic energy falls in local minimums at specific film thicknesses; thus, the film tends to align its local thickness to a particular (magic) one. The result typically is atomically flat film morphology that minimizes the electronic energy.)
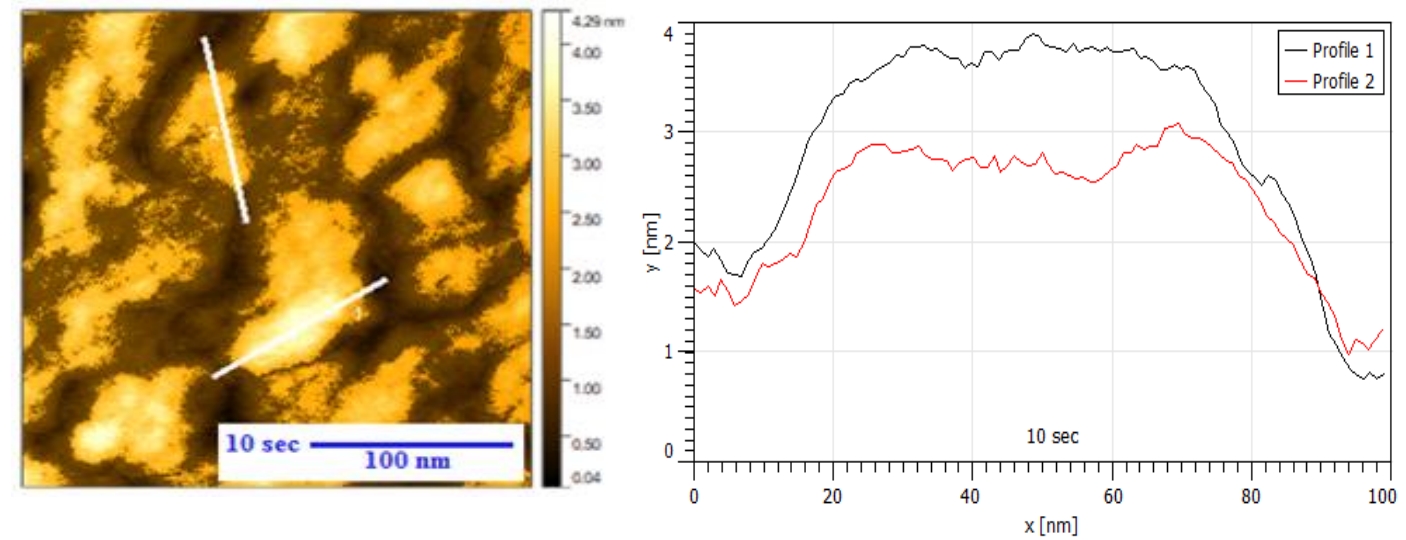

Figure 11. (a) AFM image of the surface morphology of Pb film deposited at $25^{\circ} \mathrm{C}$ for $10 \mathrm{~s}$ using laser wavelength $1064 \mathrm{~nm}$ and laser fluence $8 \mathrm{~J} / \mathrm{cm}^{2}$, and (b) the height profiles along the lines drawn on intensity AFM micrograph in (a).

A surface diffusion equation-based model was recently used to compute the coarsening of quantum nanoislands [30]. In that paper, it is shown that the 10 ML and 14 ML islands, as well as the islands of other "magic" heights, form by a 3D-to-2D transition from the round-top Stranski-Krastanow islands. $10 \mathrm{ML}$ and $14 \mathrm{ML}$ heights are metastable, but at room temperature or higher temperature, they are typically more stable than other metastable "magic" heights. This explains why these heights are present in Figure 11. In reference to the experimental results, notice the progressive "flattening" of the islands in 
Figures 6-8. This is the just mentioned 3D-to-2D transition. Lastly, it is known that increasing the temperature increases the surface diffusion.

\subsection{Crystallographic structure of $\mathrm{Pb}$ thin films}

We have also analyzed $\mathrm{XRD}$ of $\mathrm{Pb}$ thin films at different laser energy density, Fig. 9. While there is a strong peak around $\{111\}$ direction, $\mathrm{Pb}$ film also displays a preferential $\{200\},\{220\}$, and $\{311\}$ peak at all fluencies. The peak around $65^{\circ}$ is probably due to the lead silicate and lead oxide formations [31-33]. (The interaction of highly energetic $\mathrm{Pb}$ atoms and ions with physisorbed molecular oxygen and the native oxide layer during the initial stages of the growth could lead to the formation of lead silicate crystallites.) Changing the laser fluence has no effect on the peak shift. However, some peaks become sharper, signaling the enhanced crystallinity at $\{111\},\{200\},\{220\}$ and $\{311\}$ surface orientations.

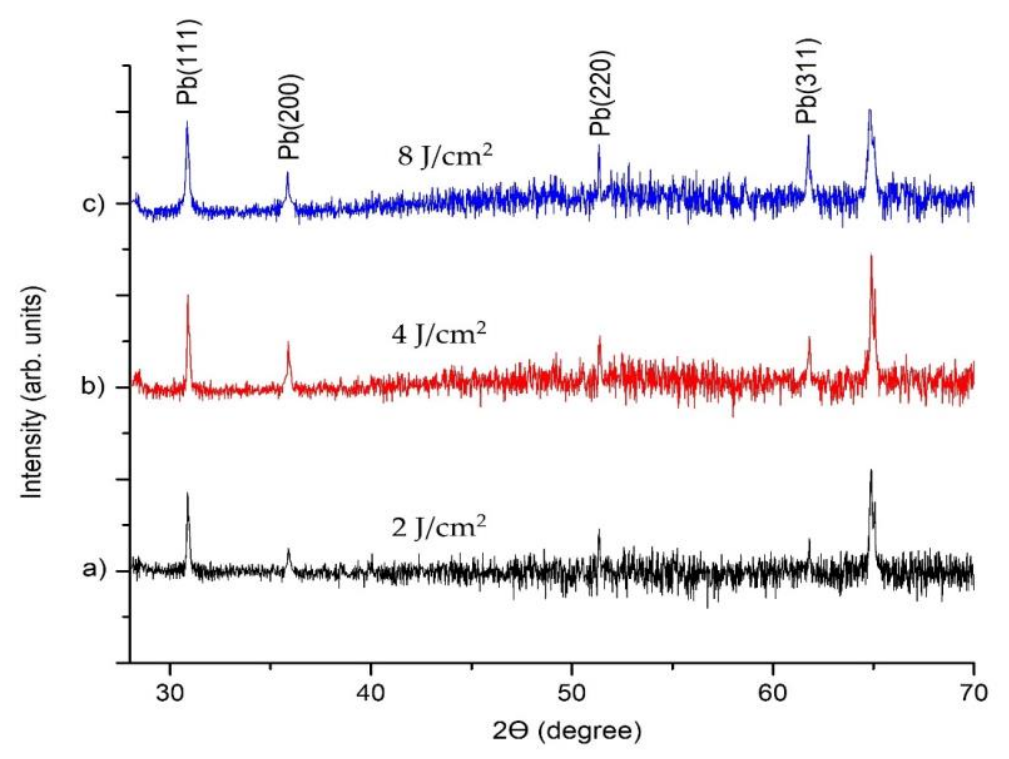

Figure 12. XRD image of the surface morphology of $\mathrm{Pb}$ film deposited for 10 minutes at $25^{\circ} \mathrm{C}$ by using $1064 \mathrm{~nm}$ wavelength at different laser fluences, (a) $2 \mathrm{~J} / \mathrm{cm}^{2}$, (b) $4 \mathrm{~J} / \mathrm{cm}^{2}$, (c) $8 \mathrm{~J} / \mathrm{cm}^{2}$. 


\section{CONCLUSION}

We have grown $\mathrm{Pb}$ thin films on Si (111) surface using PLD. Our results show that the laser parameters and the substrate temperature can be tuned to control the thickness and the morphology of the films. Although the laser fluence has no effect on the XRD peak position, it affects the crystallinity of the peak. Also, the films show a preferential crystalline structure at given fluencies. The main reason for the morphology change is likely the dynamic interplay of the islands boundary energies and the repulsive interaction between the boundaries. PLD is shown to be a feasible deposition system for lead thin films on silicon. 


\section{APPENDIX A: VACUUM SYSTEM AND OPERATIONS}

One of the essential parts of the pulsed laser deposition system. Since all deposition process occurs inside of the vacuum chamber. The vacuum system can be separated into for main parts.

1. Ultra high vacuum chamber

2. Pumping system

3. Sample holder

4. Target holder

Ultra high vacuum chamber.

This spherical chamber made of 304L stainless steel metal. The diameter of the chamber is 16 inches, and the thickness of the wall is 0.125 inches. It is bakeable up to 400 Celsius degree to clean the vacuum chamber from water vapors. UHV chamber has eight equally spaced 2.75 inches ports that are terminated with transparent glass for light source entering and observation. Almost ten percent of the light reflects from this transparent glass. One of them closed with a special valve for background gas. There are two ports with a 6-inch diameter in front and back. These ports are used for sample holder and target holder systems. Three ports with an 8-inch diameter are located on the top and sides. They are used for a camera system to observe the plasma plume expansion. The largest port with a 10-inch diameter of the UHV chamber is located at the bottom, and it used form the evacuation system. The UHV chamber is shown in Figure A1. 


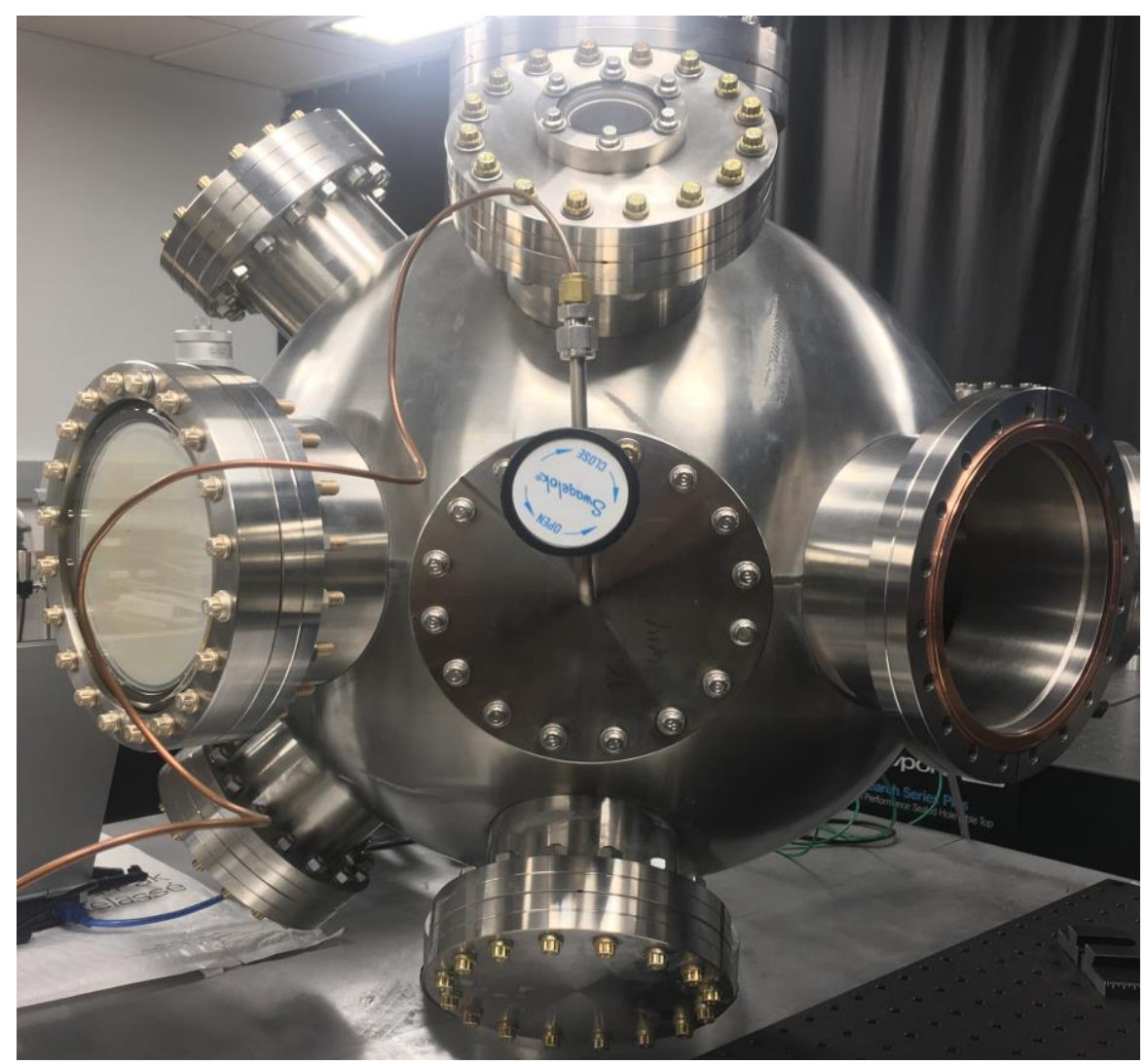

Figure A1. Ultra high vacuum chamber.

\section{Evacuation of UHV chamber.}

In our evacuation system, we used three types of pumps. The first one is a mechanical pump presented in Figure A2. This Agilent Technologies' SH110 Dry Scroll Pump is suitable for pumping air or inert gases. The pump is not intended to evacuate corrosive, explosive, or particulate-forming gases. Main technical specifications of the pump are followings:

- Pumping speed: $90 \mathrm{~L} / \mathrm{m}$ at $50 \mathrm{~Hz}$ and $110 \mathrm{~L} / \mathrm{m}$ at $60 \mathrm{~Hz}$.

- Ultimate pressure: $5 \times 10^{-2}$ Torr $\left(6.6 \times 10^{-2} \mathrm{mbar}\right)$.

- Operating voltage: 50-60 Hz 100-115:200-230 VAC 


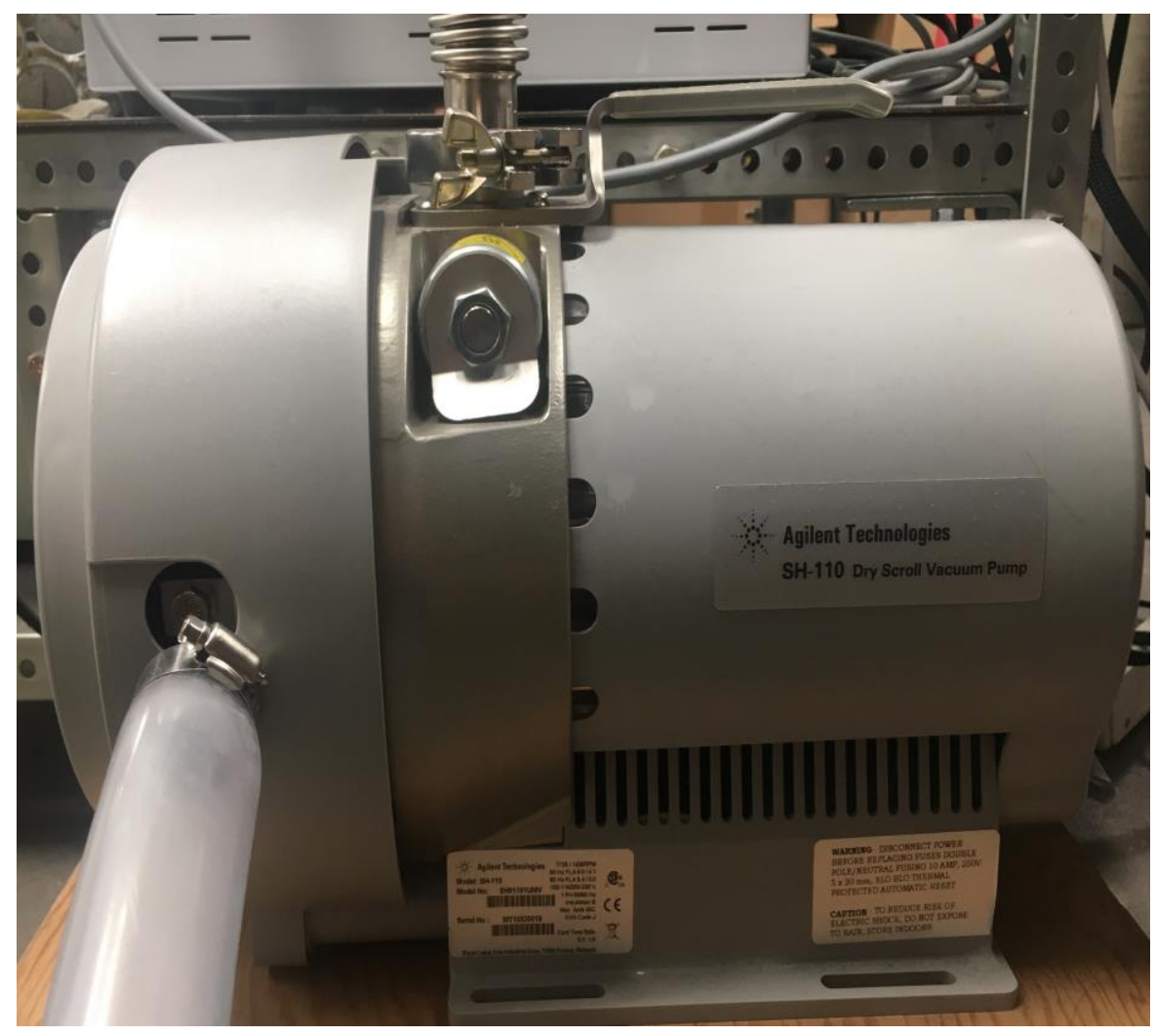

Figure A2. Mechanical pump.

The second one is a turbopump designed by Agilent Technologies. The turbine fitted highfrequency motor of this TwisTorr 304 pump has three TwisTorr drag stages and eight bladed stages. The turbine made of high strength aluminum alloy. It stops to operate if the temperature sensor detects more than 60 Celsius degree. Therefore, it should always be cooled by air cooler. Main technical parameters of the pump are followings:

- Pumping speed: $250 \mathrm{~L} / \mathrm{s}, 1500 \mathrm{~L} / \mathrm{m}$.

- Rotational speed: $60000 \mathrm{rpm}$ (1010 Hz driving frequency of the motor).

- Base pressure: $<1 \times 10^{-10}$ Torr $\left(<1 \times 10^{-10} \mathrm{mbar}\right)$.

- Operating ambient temperature: $+5{ }^{\circ} \mathrm{C}$ to $+35^{\circ} \mathrm{C}$. 
- Operating voltages: 50-60 Hz 100-115:200-230 VAC

In our system, the mechanical pump and turbopump are controlled by the Agilent Technologies pump controller presented in Figure A3. Black knob with number 1 used to turn on and turn off the mechanical pump, and button number 2 used to operate and stop the turbopump.

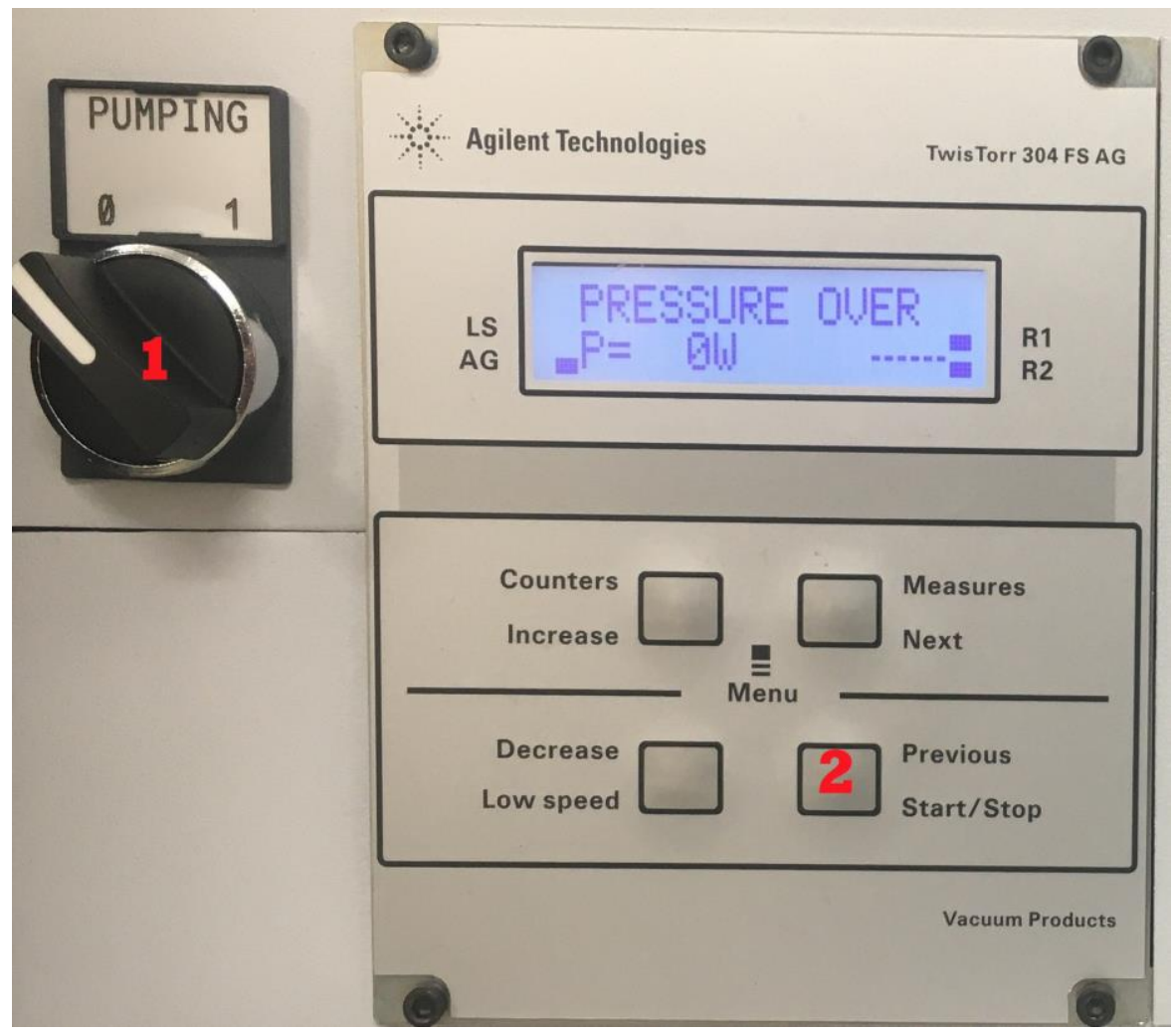

Figure A3. Mechanical and turbopump controller.

The last pump is Vaclon Plus 300 ion pump designed by Agilent technologies shown in Figure A4. This pump operates in the pressure ranging from $10^{-2}$ to $10^{-11}$ mbar. All gases and vapors can be evacuated successfully with an ion pump. The speed of the pump depends on the system pressure, types of gases, and used voltage level and frequency to operate. 


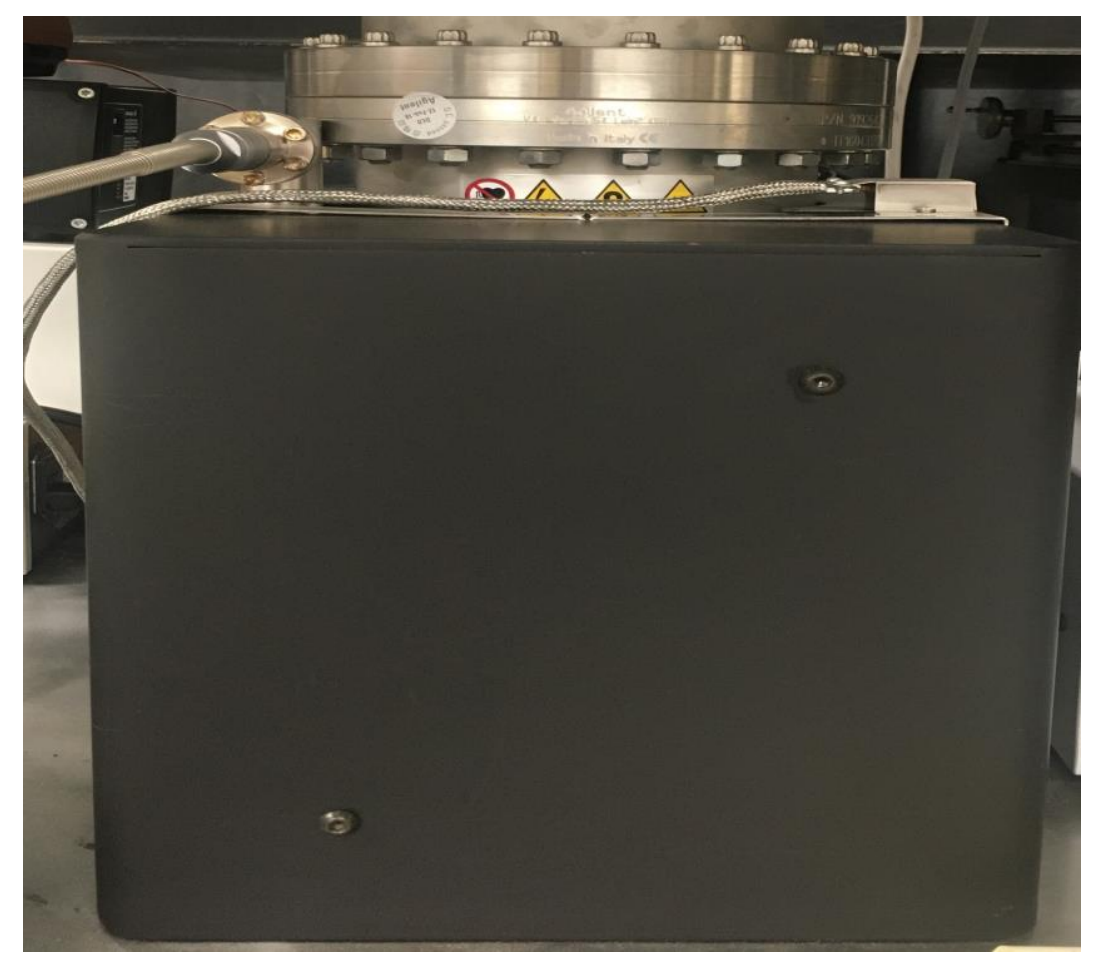

Figure A4. Ion Pump.

Main technical parameters of the ion pump are:

- Nominal pumping speed: $300 \mathrm{~L} / \mathrm{s}$.

- Ultimate pressure: $10^{-11}$ mbar

- Operating voltage 7000 Volt

- Maximum baking temperature: $350^{\circ} \mathrm{C}$

Agilent Technologies' 4UHV Ion Pump Controller, presented in Figure A5, used to operate the ion pump. Buttons number 1 and number 2 pressed together simultaneously to turn on the pump and pressed together to stop it. Digital displays on the controllers show pressure inside the UHV chamber in torr. 


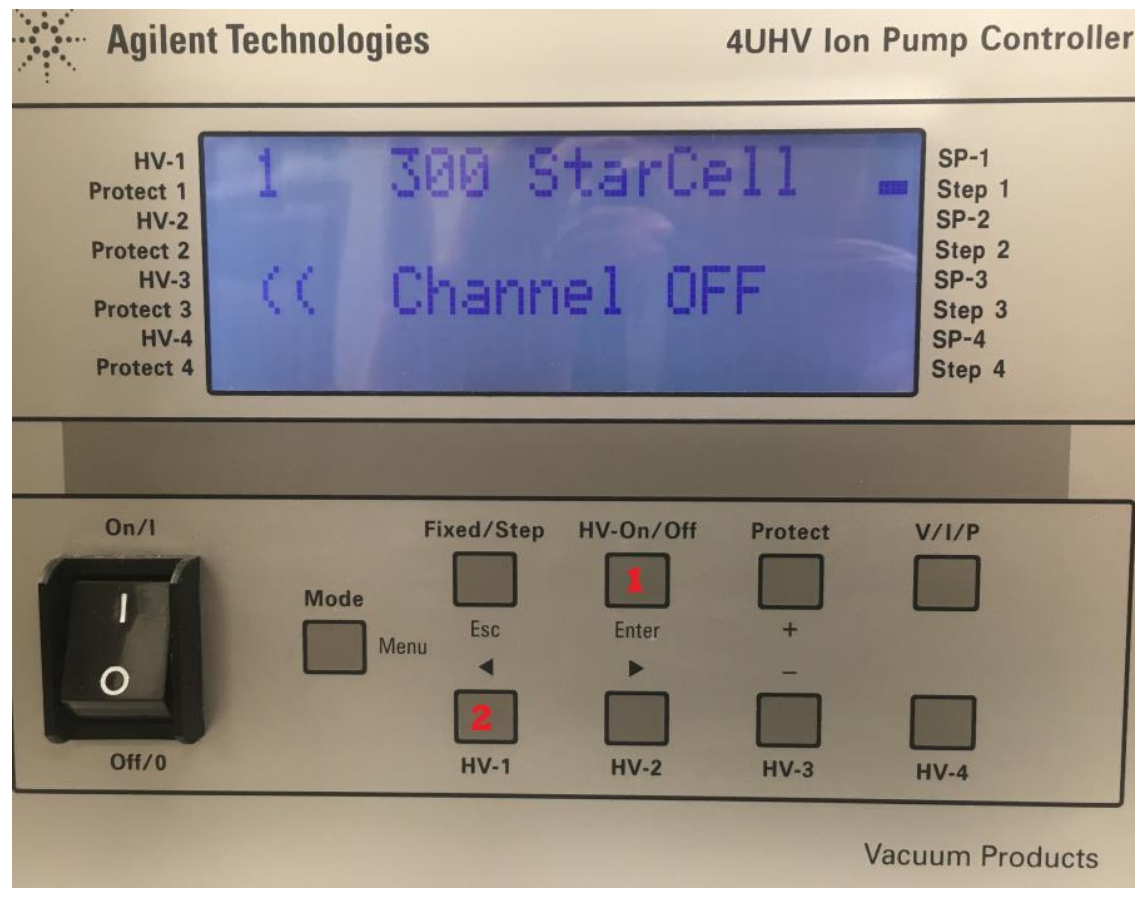

Figure A5. Ion pump controller.

Steps for evacuation.

1. Make sure that there is no leakage, including the vent valve of the turbopump.

2. Open right angle valve of the UHV chamber.

3. Operate mechanical pump until pressure decreases to $10^{-2}$ torr.

4. Operate turbopump until pressure decreases to $10^{-6}$ torr.

5. Turn on the ion pump.

6. Close the right angle valve of the UHV chamber when both controller displays show nearly equal pressure level.

7. Turn off turbopump

8. Turn off the mechanical pump 
9. Very slowly open the vent valve by tracking the pressure and motor speed of the turbopump.

\section{Steps for ventilation.}

1. Completely close the vent valve of the turbopump.

2. Turn on the mechanical pump.

3. Turn on turbopump.

4. Open the right angle valve of the UHV chamber when the pressures of the turbopump and ion pump are nearly equal to each other.

5. Turn off the ion pump.

6. Turn of turbopump.

7. Turn of the mechanical pump.

8. Very slowly open the vent valve by tracking the pressure and motor speed of the turbopump.

Substrate holder and heating.

The substrate holder is a mechanical construction made of high stainless steel alloy. There are mainly five parts, including a heating system and temperature sensor, as shown in Figure A7. 


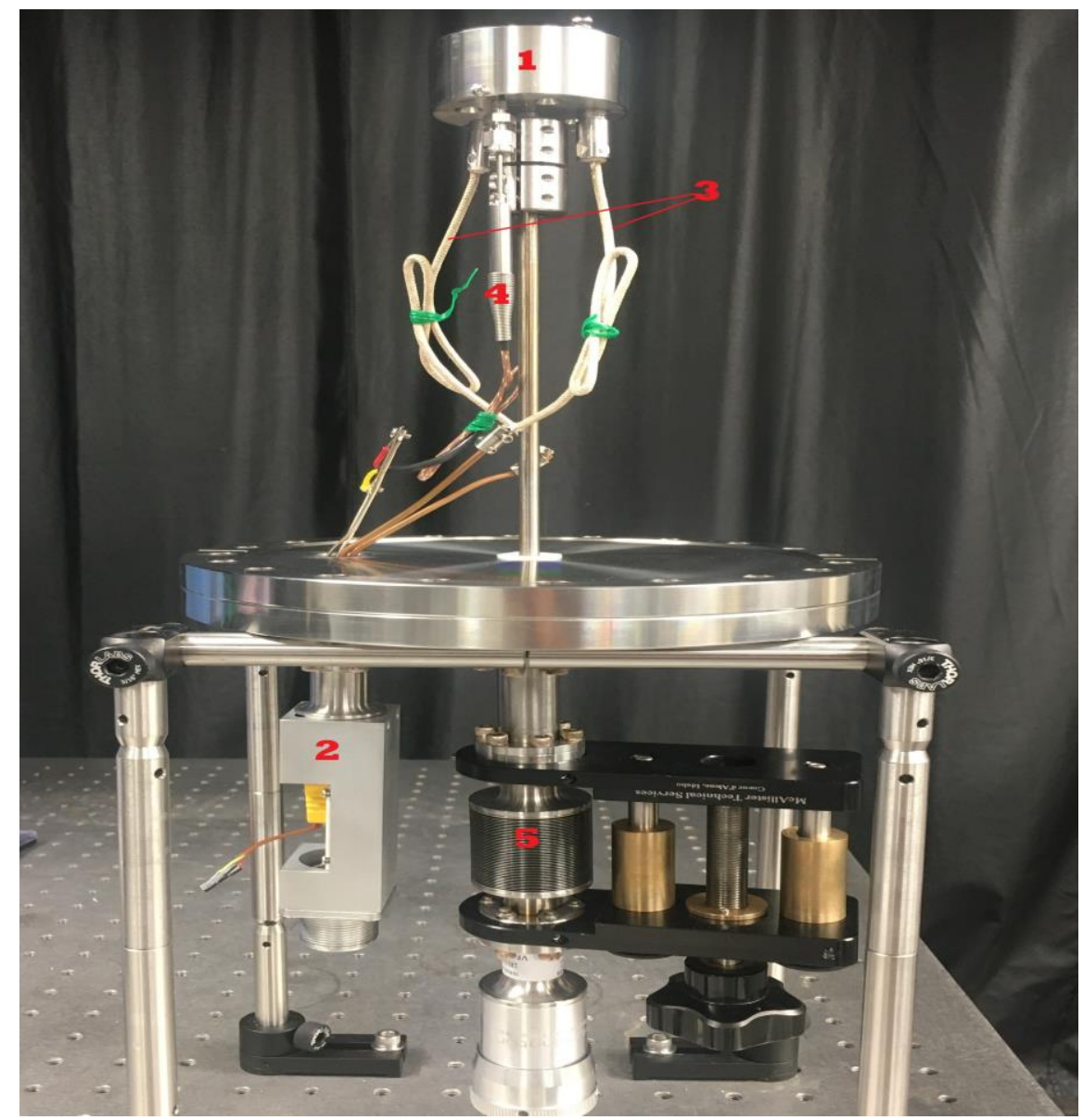

Figure A7. Sample holder system.

1. Sample holder with boron nitrate heater.

2. Terminals for Ohmic heater and thermometer for measurement.

3. Copper wires for positive and negative terminals of the DC power supply.

4. Thermocouple to measure the substrate temperature.

5. Mechanical constriction to move the sample holder back and forth to adjust the distance between target and substrate material.

In Figure A8 presented the uploaded sample to the heater. Commercially available P-type, B-doped, high crystal Si (111) substrate with 10mmx 10mmx0.5mm dimensions obtained from MTI corporation. The boron nitrate heater with 1-inch size has a 
temperature uniformity within ten percent and can heat up to $1000-1100^{\circ} \mathrm{C}$ in annealing and deposition processes in a vacuum. BN heater designed and manufactured by Blue Wave Company, and it includes a stainless steel shield with six tapped holes for sample clamping. The K-type thermocouple is mounted from the back, approaching the hot surface for accurate temperature measurement. The two insulated flexible 36-inch long glass fibers conductor wires are inbuilt for power supply. Titanium clippers used to hold the substrate.

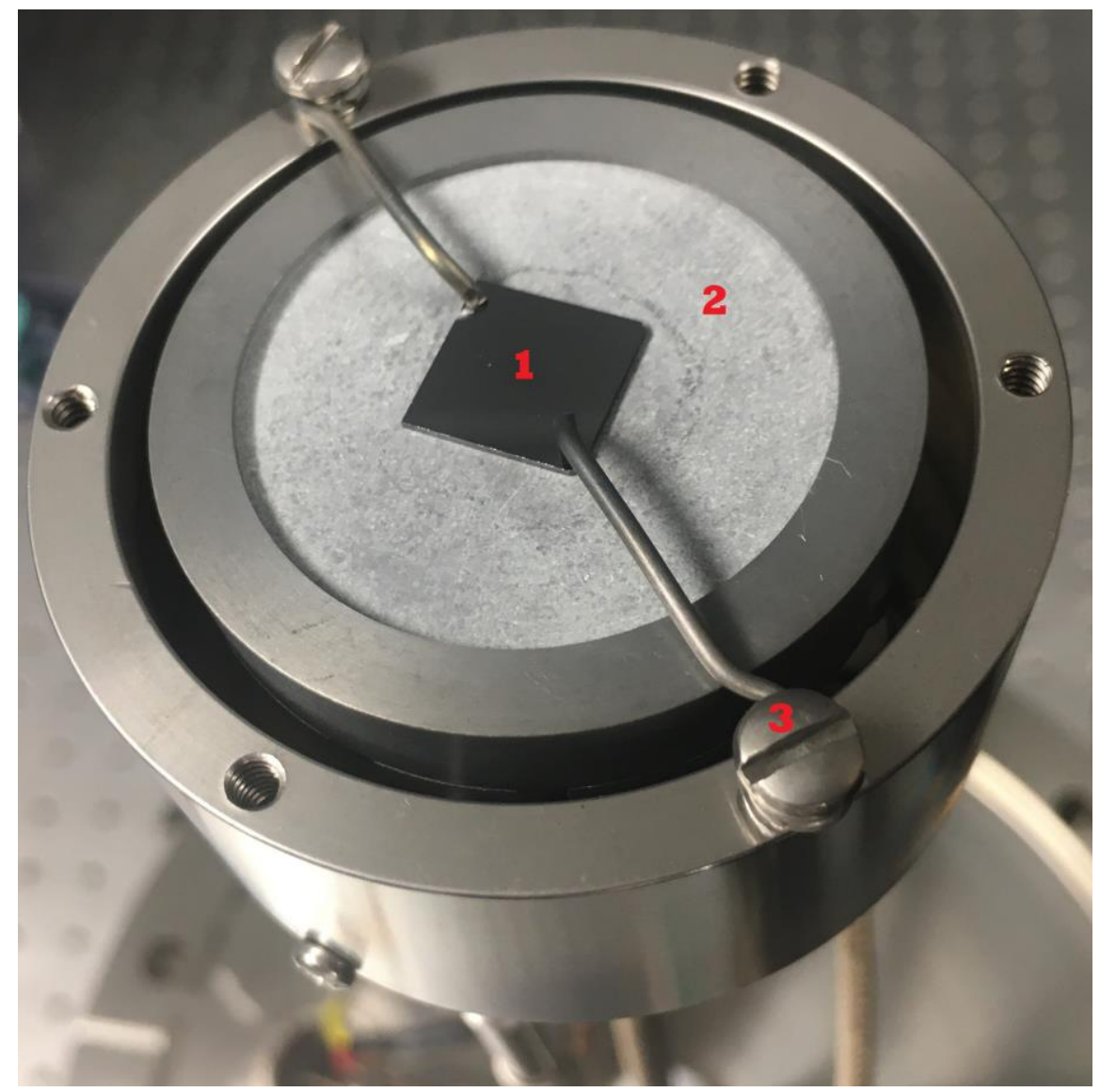

Figure A8. Uploaded sample.

1. Silicon substrate

2. Boron Nitrate heater 


\section{Titanium clipper}

\section{Target and target holder.}

The mechanical constriction of the target holder is presented in Figure A9. It contains five parts, including a microcontroller. All five elements are used to move and rotate the target to ablate it homogeneously.

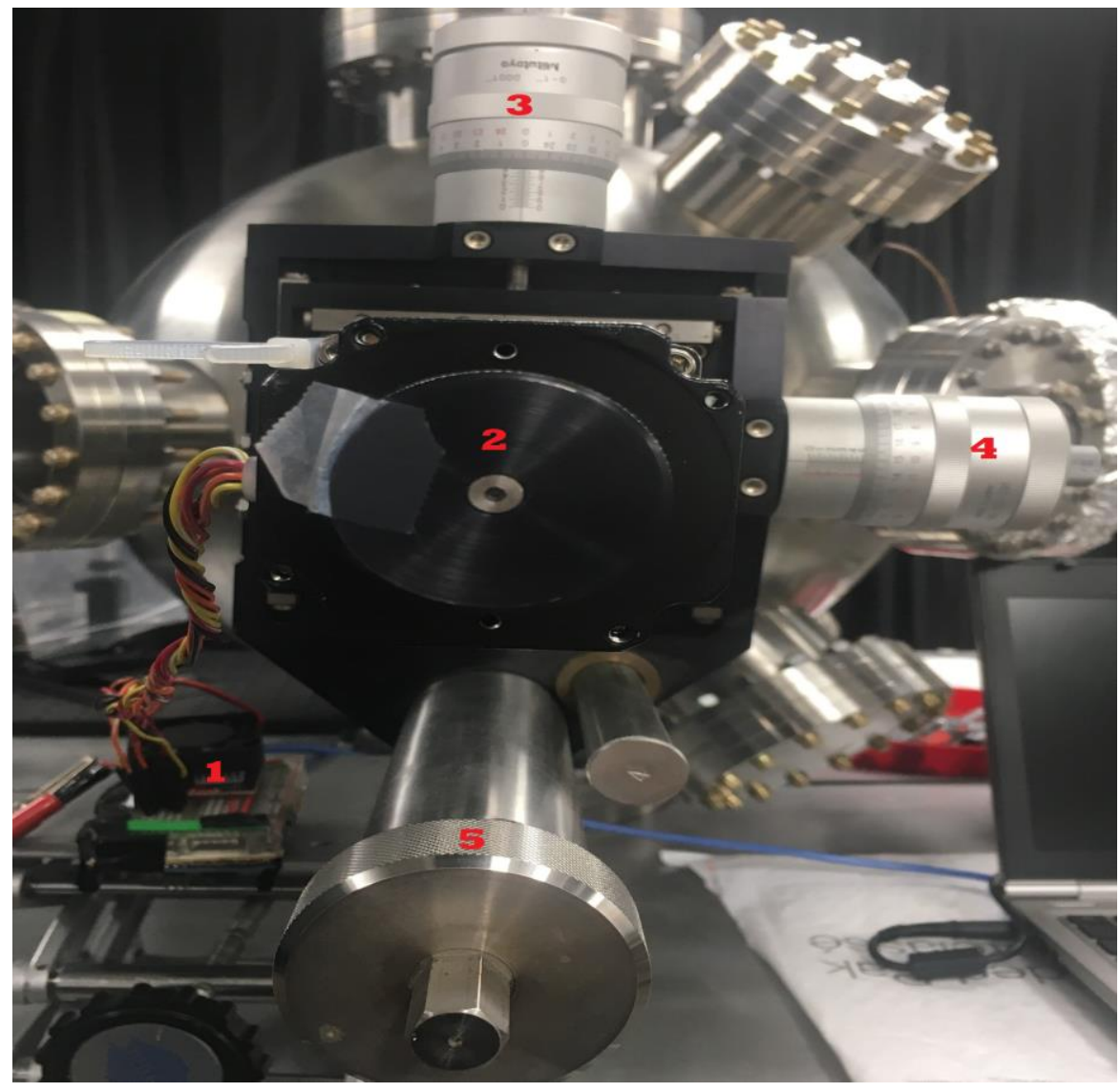

Figure A9. Target holder.

1. Arduino Uno microcontroller.

2. Step motor.

3. Rotational micrometer size stage to move the target up and down.

4. Rotational micrometer size stage to move the target right and left. 
5. Mechanical structure to move the target back and forth.

Arduino code used to control the step motor for rotation is:

//Declare pin functions on Redboard

\#define stp 3

\#define dir 2

\#define MS1 8

\#define MS2 13

\#define EN 12

//Declare variables for functions

int $\mathrm{x}$;

int user_input=0;

int rpm;

unsigned long timer=0;

unsigned long rpm_tdelay;

unsigned long tfStart $=0$;

unsigned long tfEnd=0;

unsigned long initialf;

unsigned long timetoshow;

void $\operatorname{setup}()\{$

pinMode(stp, OUTPUT);

pinMode(dir, OUTPUT);

pinMode(MS1, OUTPUT); 
pinMode(MS2, OUTPUT);

pinMode(EN, OUTPUT);

resetEDPins(); //Set step, direction, microstep and enable pins to default states

Serial.begin(9600); //Open Serial connection for debugging

Serial.println("Begin motor control");

Serial.println();

Serial.println("Turn at full microstep mode.");

Serial.println();

Serial.println("Please enter the time for the motor to be working in minutes: ");

float time_income_from_user $=0$;

while(time_income_from_user==0) // loop to wait until user makes a choice

\{

time_income_from_user=Serial.parseFloat();

delay(1);

\}

Serial.println("The time your entered is: ");

Serial.print(time_income_from_user);

Serial.print(" ");

Serial.print("minutes");

Serial.println("');

Serial.println("The time your entered is: ");

Serial.print(time_income_from_user*60);

Serial.print(" "); 


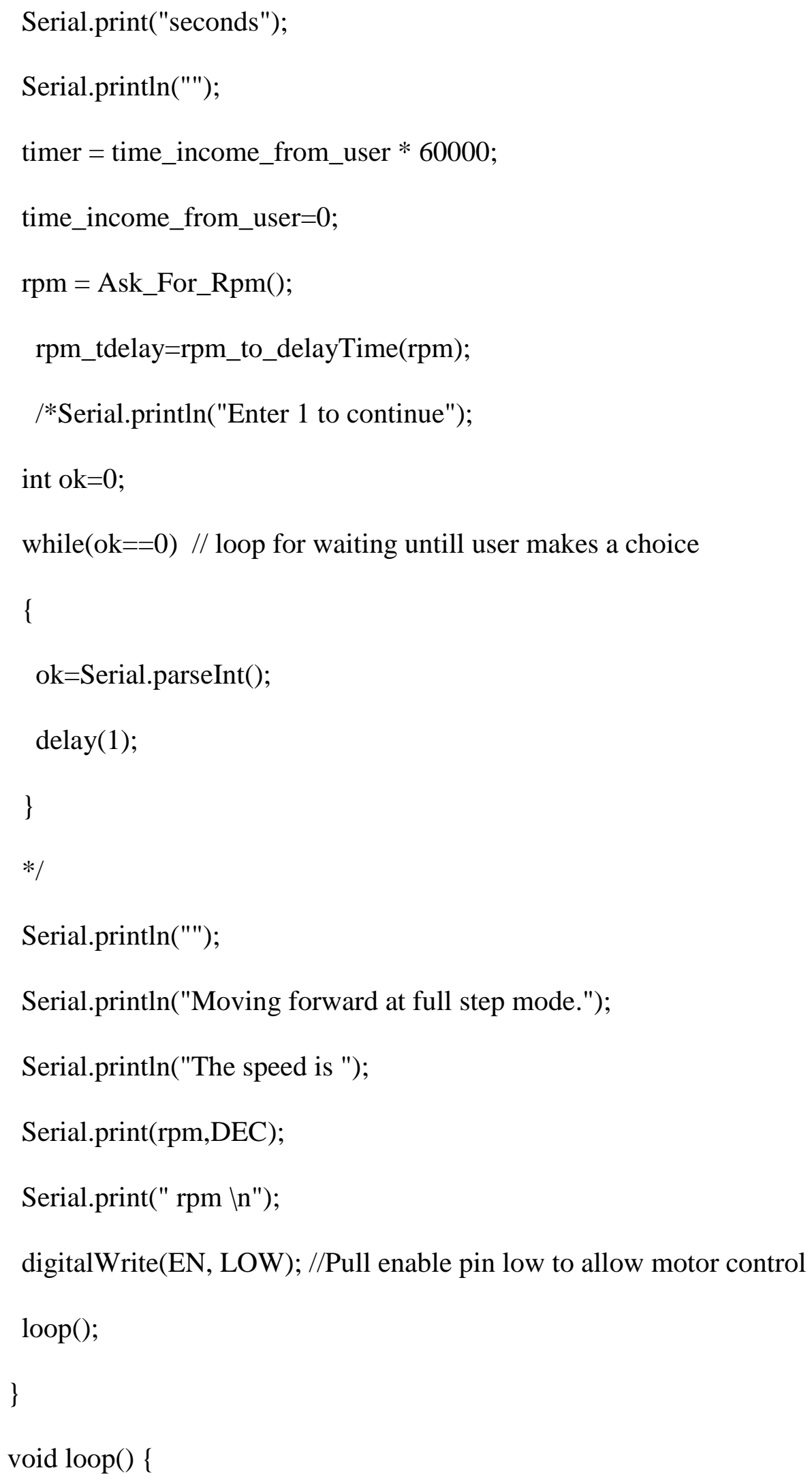




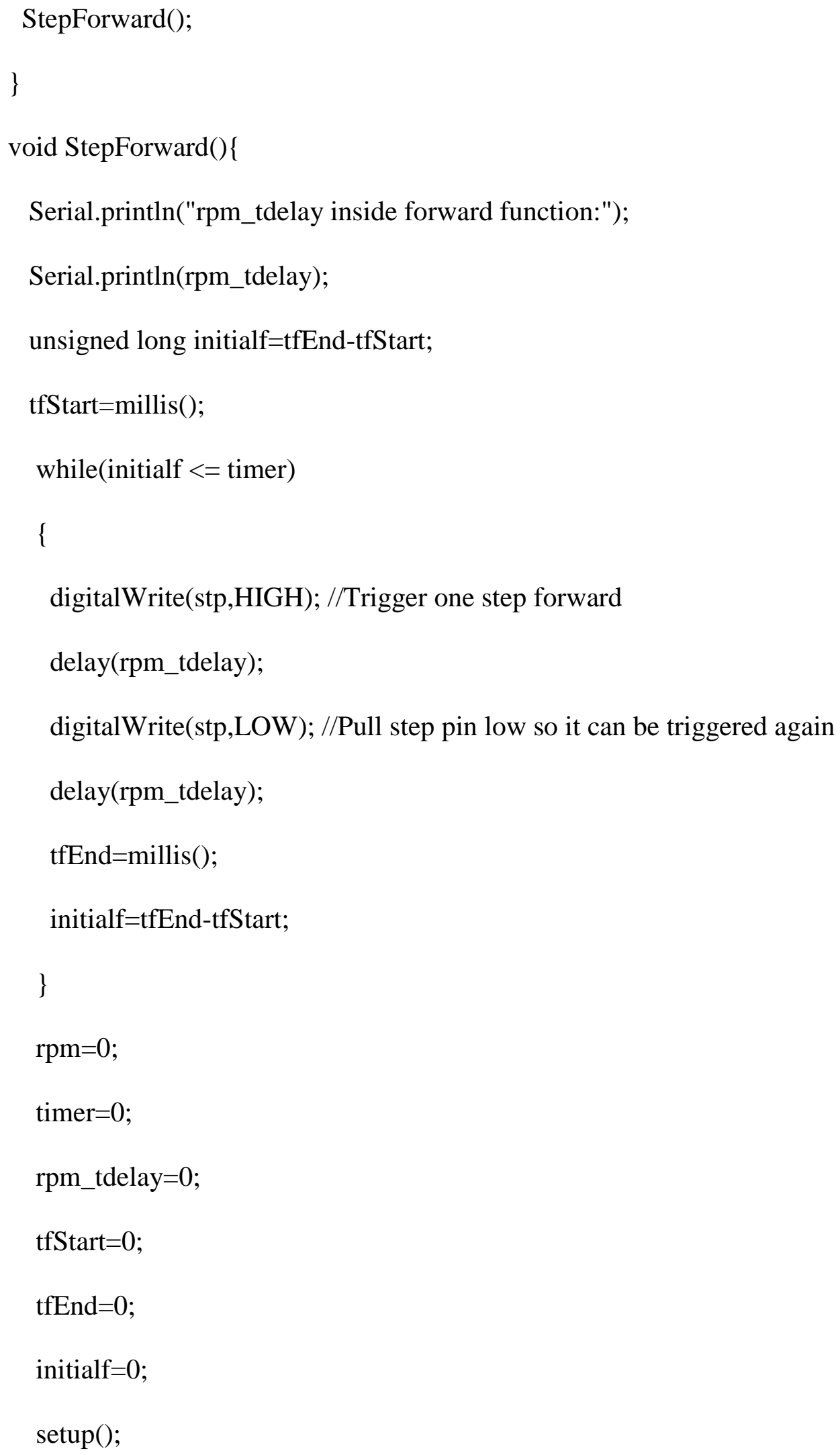




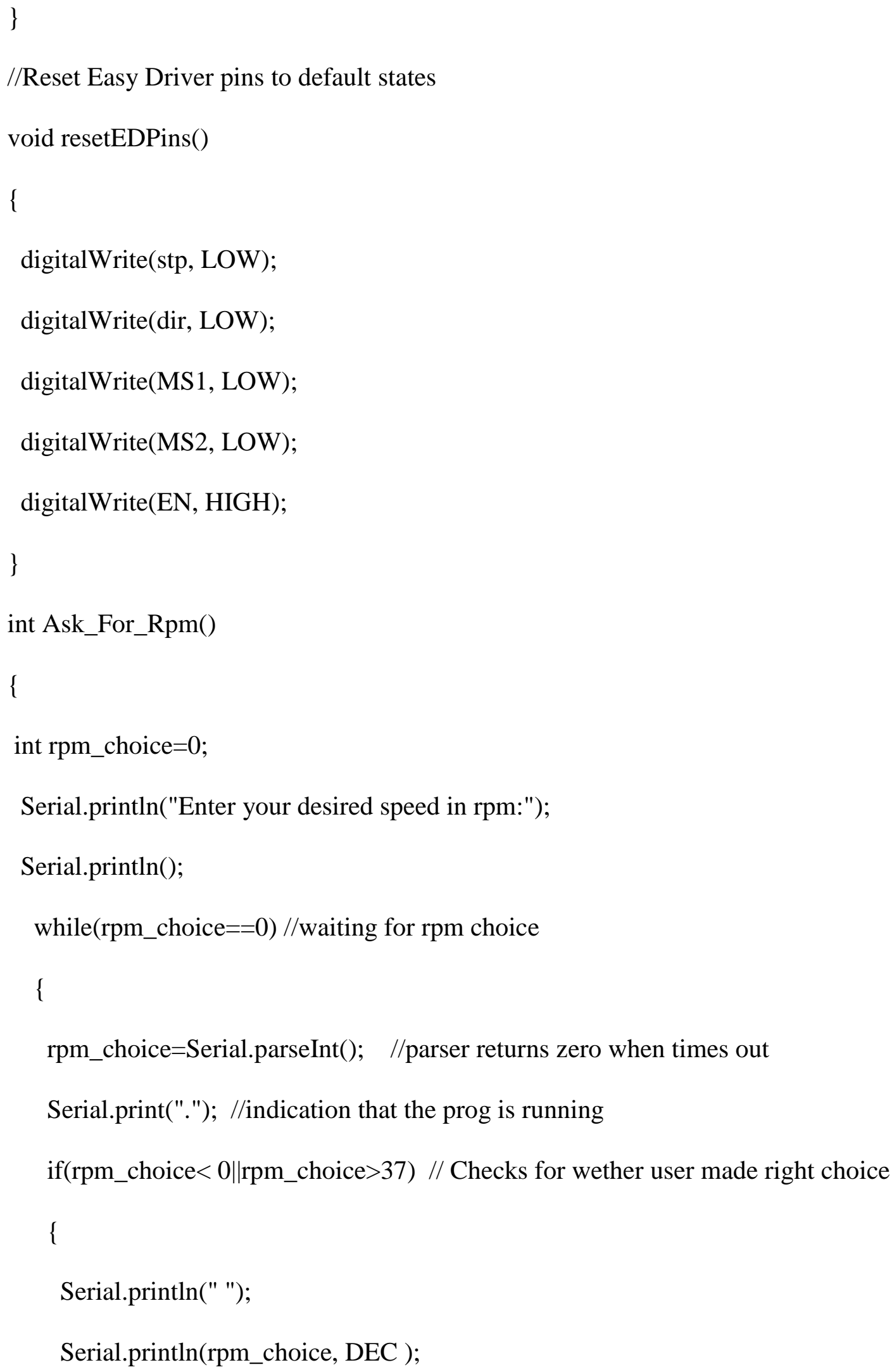




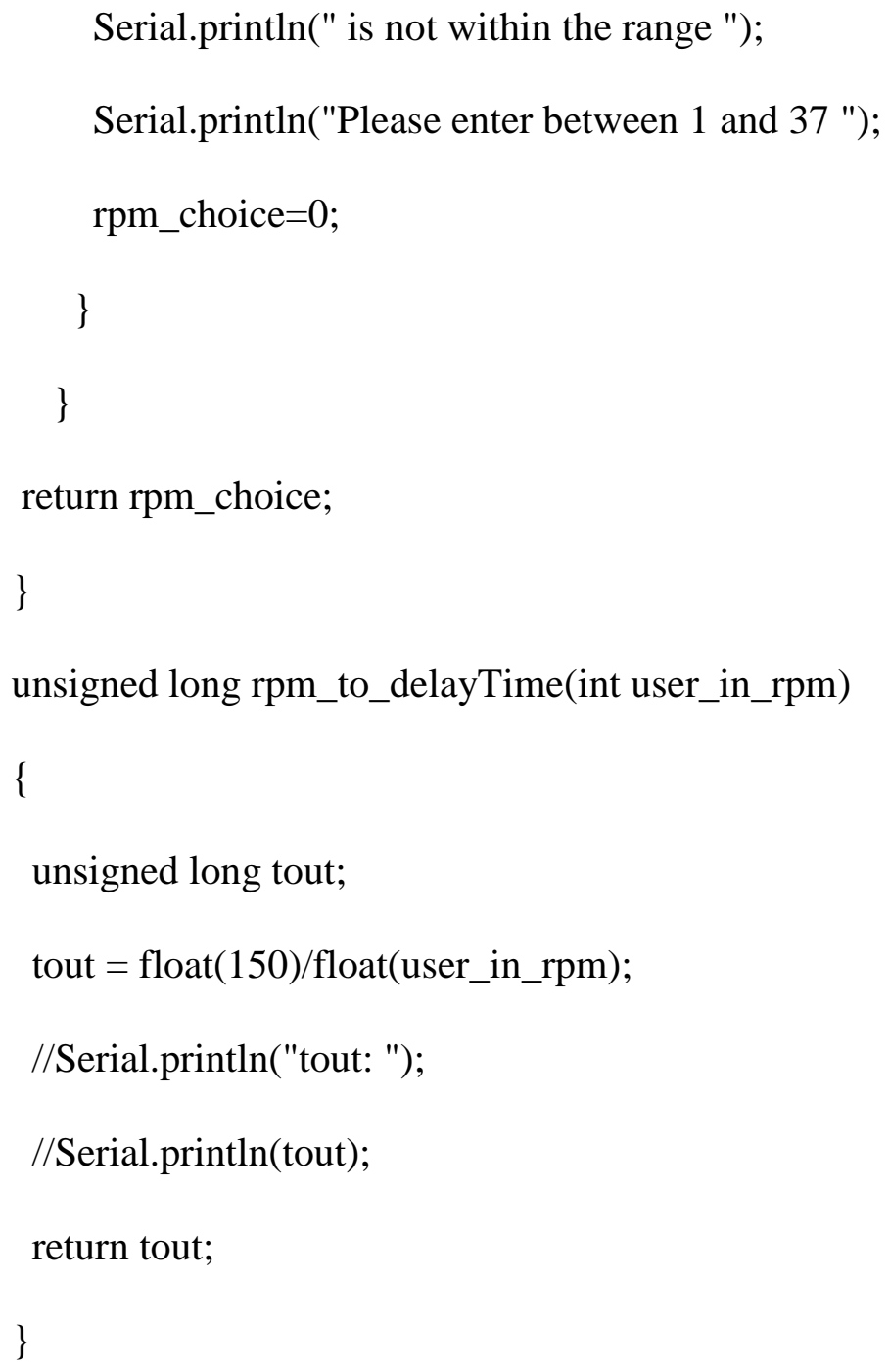

A commercially available pure $99.99 \% \mathrm{~Pb}$ bulk material (Figure A10) with a diameter of $6 \mathrm{~cm}$ is used as a target material. It attached with a special glue that can hold in a high vacuum to the target holder. Target holder designed and manufactured in a machine shop of Western Kentucky University, and it made off an aluminum. 


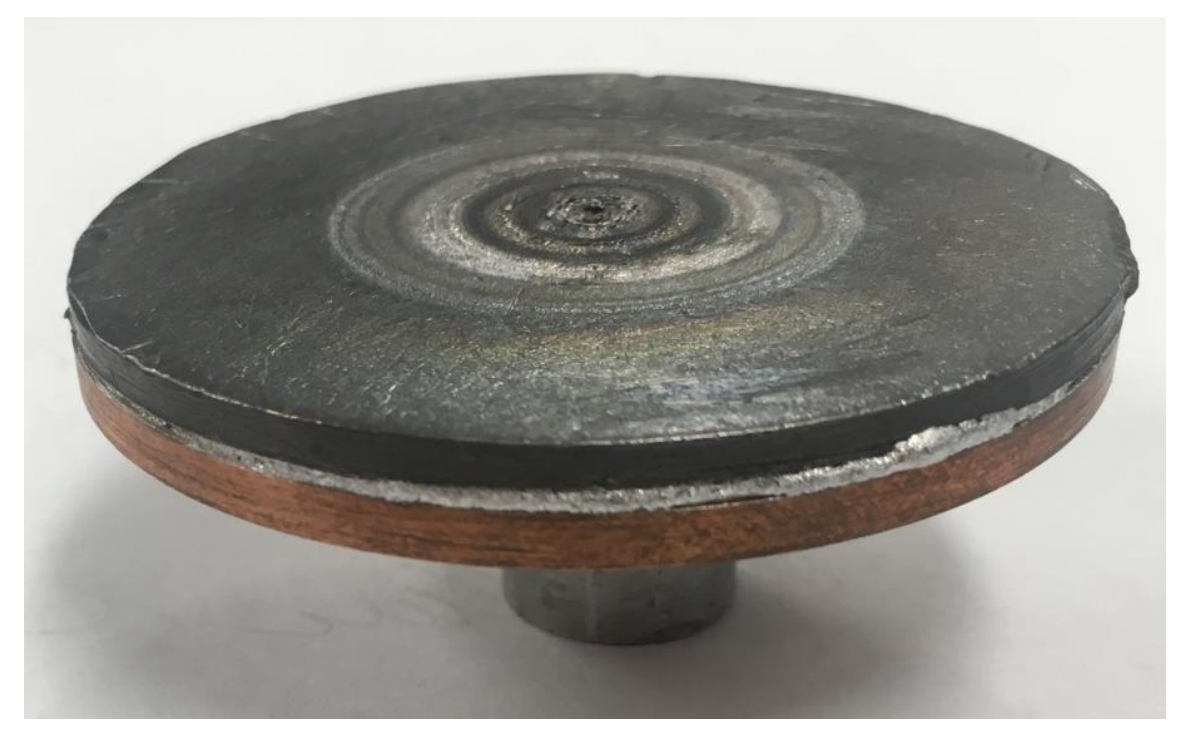

Figure $\mathrm{A} 10 . \mathrm{Pb}$ target.

\section{APPENDIX B: Nd: YAG LASER OPERATION}

Deionized cooling water is used for cooling purposes. To operate the laser cooling water should be checked every month.

\section{Turn ON}

1. Before operating the laser danger sign must be attached outside of the laser lab, and everyone inside the lab must wear safety goggles.

2. Turn ON laser by rotating the key-switch to counter-clockwise direction, as shown in Figure B1. If the yellow light does not appear on the laser ON button, something went wrong. When the key-switch at 'I' position, the LED screen will run through a three-set of 3 digit numbers. These numbers " $\mathrm{A}_{1} \mathrm{~A}_{2} \mathrm{~A}_{3}, \mathrm{~B}_{1} \mathrm{~B}_{2} \mathrm{~B}_{3}, \mathrm{C}_{1} \mathrm{C}_{2} \mathrm{C}_{3}$ " in the order they appear on LED make up the number of shots the laser has been shooting since the last reset. The light pump tube of the laser must be changed after 30,000,000 shots. 


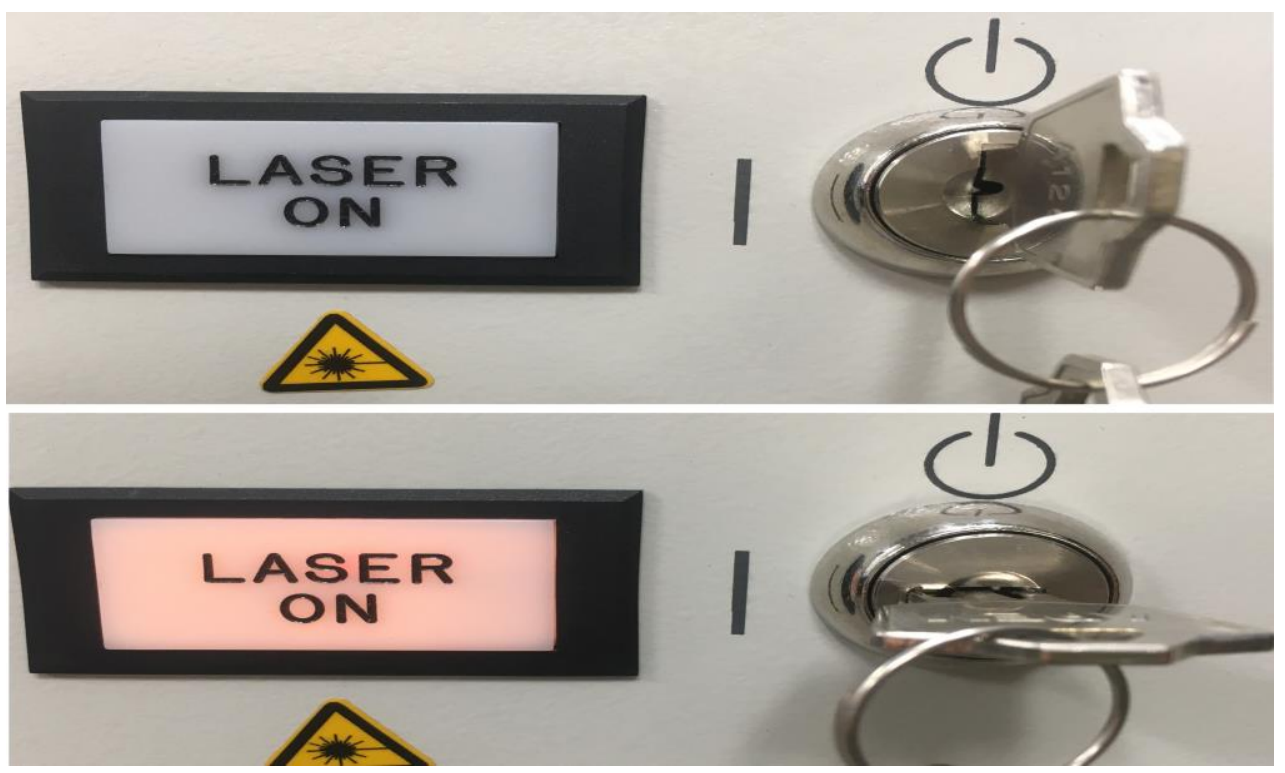

Figure B1. Key-switch positions.

3. Wait approximately 10-15 seconds until water flow starts to cool the laser during the operation.

4. Make sure all shutters are closed. The shutter button on the control panel must be turned off, and the slider in front of the laser must be moved entirely to the right, as shown in Figure B2.

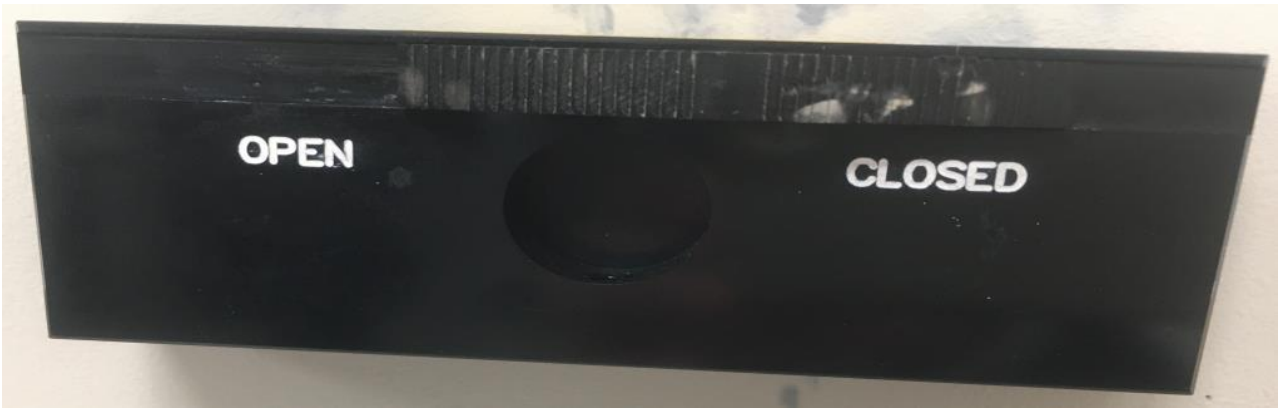

Figure B2. Slider in front of the laser. 
5. The SELECT button on the control panel is used to toggle between various settings to change the laser parameters. By pressing UP and DOWN buttons next to the SELECT button required parameters can be adjusted. The metrics presented in Figure B3 can be described by the following. P00 is single shot mode. A laser generates a single pulse beam. P01 is a continuous mode. The laser generates a continuously pulsed beam. F10 refers to the frequency of the laser. 225 is a Q-switch parameter. This parameter is significant in controlling the energy or fluence of the laser. The energy of the laser beam and Q-switch are inversely proportional. The last one is the voltage supplied from the power supply.

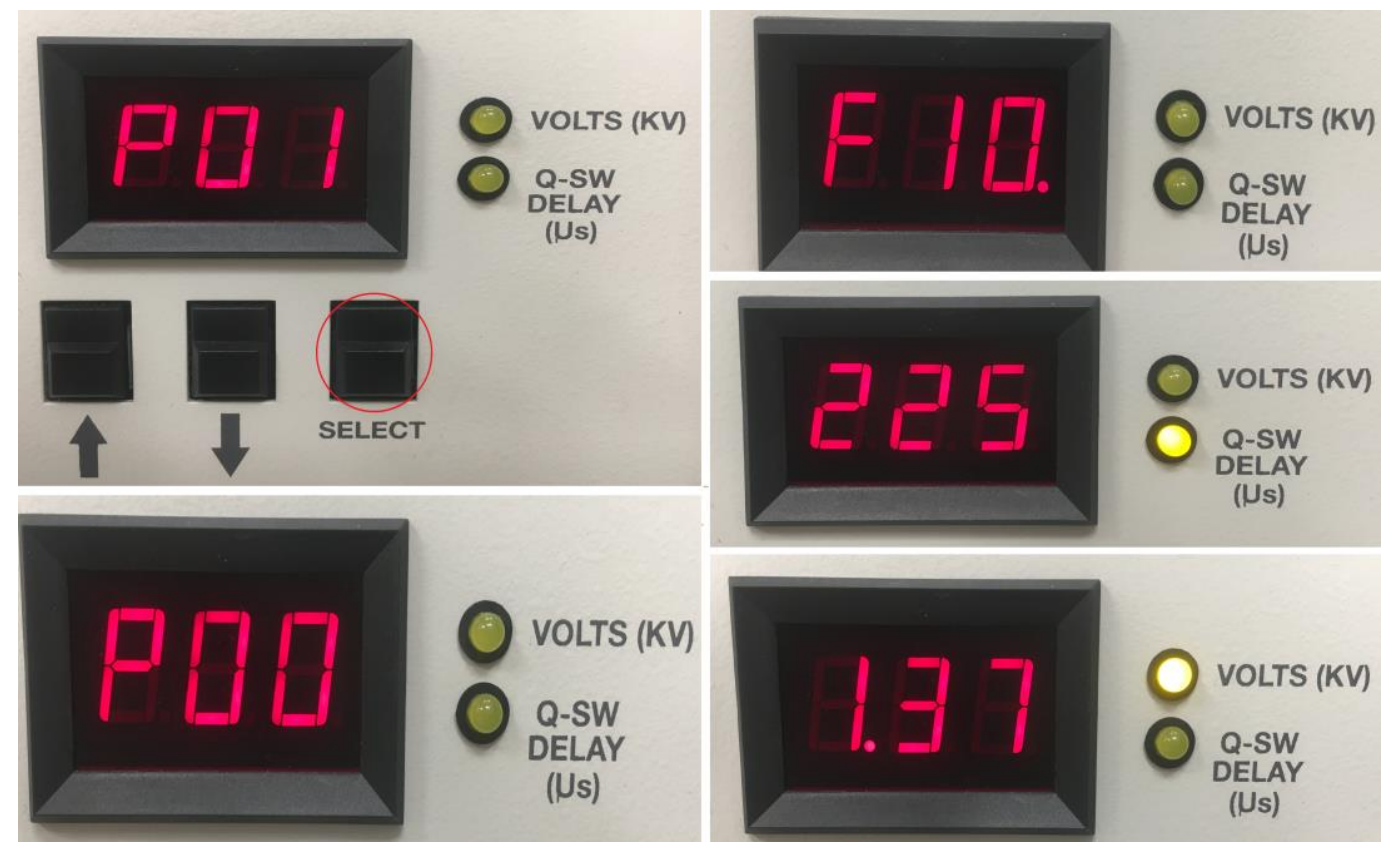

Figure B3. Controlling laser parameters.

6. After all the required parameters are adjusted, the next step is to press the button START/STOP shown in Figure B4. Wait about 5 minutes and when the laser warms up, press the button SHUTTER next to the START/STOP button. When the buttons pressed small yellow LEDs turn on located the buttons. 


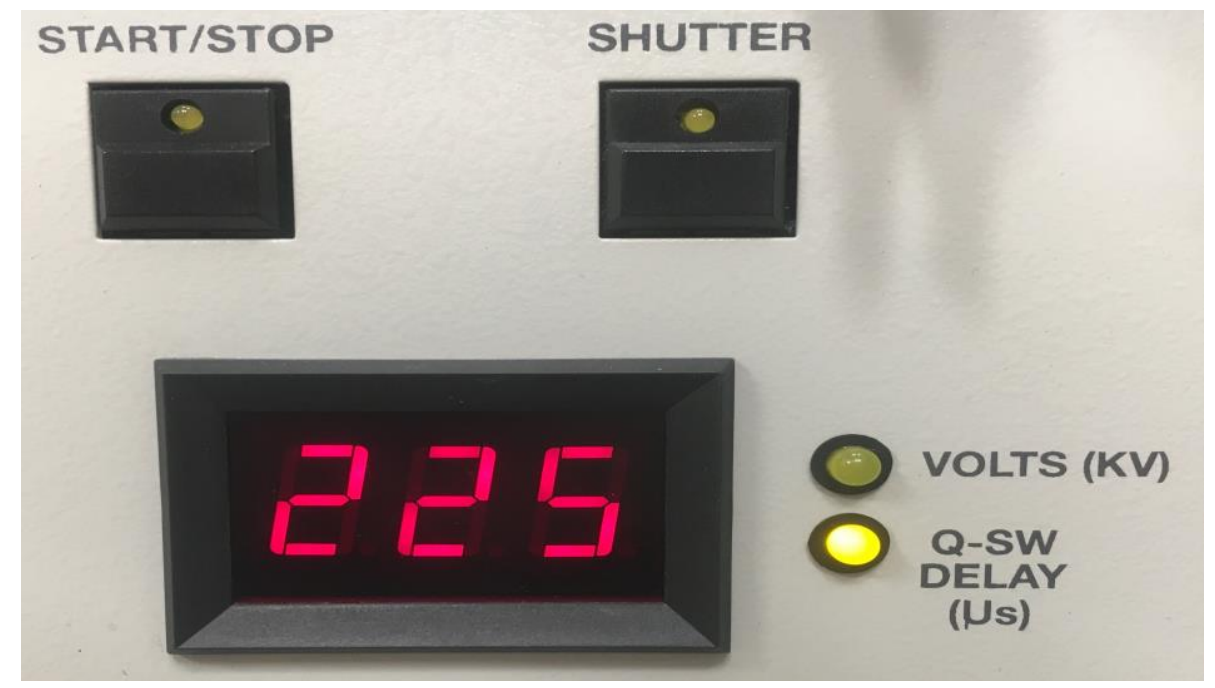

Figure B4. START/STOP and SHUTTER buttons.

7. Always start with a single shot mode. Open the shutter in front of the laser by sliding the black knob from right to left. The remote controller shown in Figure B5 allows changing the operating mode from single shot to continuous pulse mode. By pressing once the button on the remote controller, a single shot can be generated. The laser automatically starts to generate a continuous pulse when the button pressed for 5 seconds. By pressing the same button once can be switched to single shot mode.

8. Make sure that everyone is wearing safety goggles. Follow the expected path of the laser beam and make sure that the final destination of the route is the target. Open the shutter at the front of the laser by sliding it to the left (Figure B2).

\section{Turn OFF}

1. Press the single shot button from the remote controller to stop the laser.

2. Press the SHUTTER button and make sure that the LED on the button turned off. 
3. Slide the shutter in front of the laser to the right.

4. Toggle the parameters until P00 appears on display by pressing the SELECT button.

5. Press the UP button to change the mode from P00 to P01.

6. Press the START/STOP button to stop the laser and make sure the LED on the button turned off.

7. Wait for 5 minutes to cool down the laser. Then rotate the key switch to the clockwise direction to turn off the laser.

8. Cover the optics with plastic bags to prevent dust formation.

\section{APPENDIX C: OPTICAL EQUIPMENT}

Special lenses, beam splitter, full reflective mirrors, irises, half-wave plates, and polarizers are used to control the laser beam. Figure $1 \mathrm{C}$ presents the beam control process.

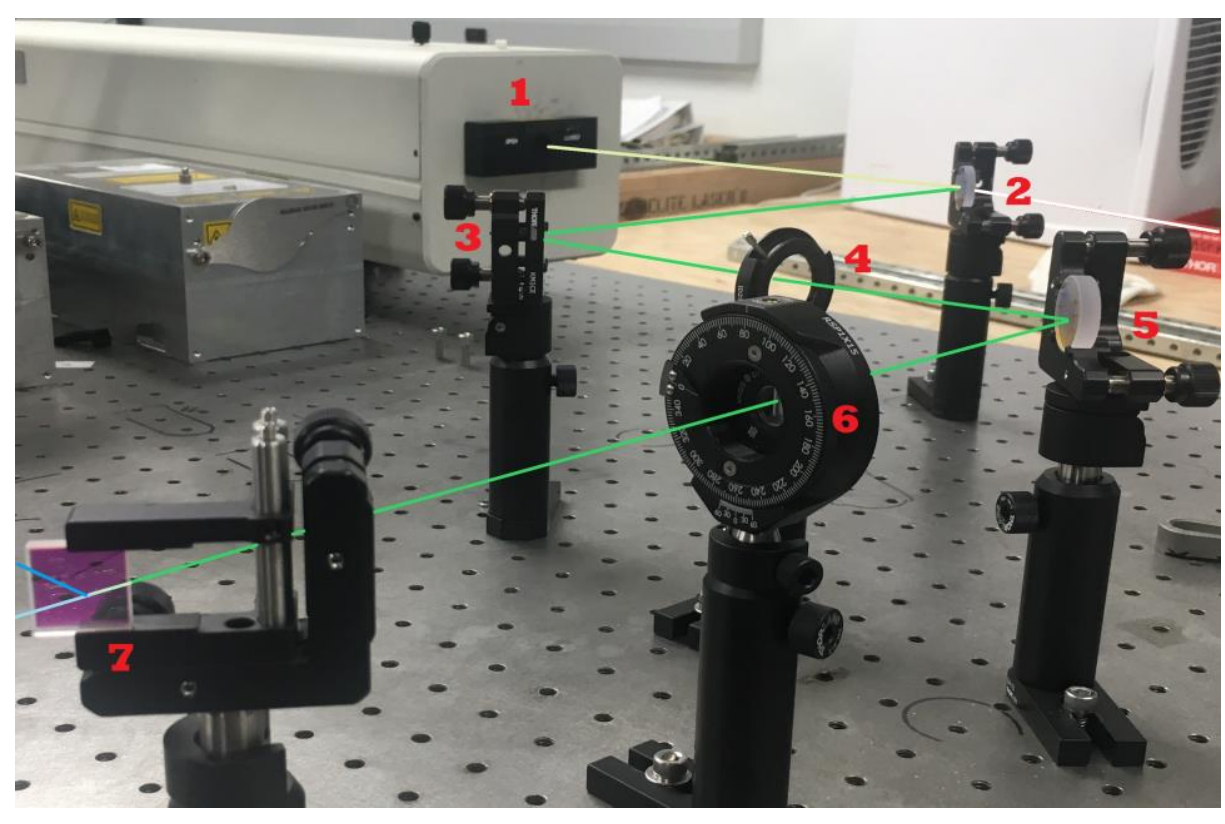

Figure C1. Beam control process. 
1. The gate used to open and close the Nd: YAG laser beam.

2. The beamsplitter, designed by Thorlabs Company, used to separate $532 \mathrm{~nm}$ and 1064 $\mathrm{nm}$ harmonics of the beam. This 1 -inch diameter fused silica substrate reflects $532 \mathrm{~nm}$ and transmits a $1064 \mathrm{~nm}$ wavelength beam.

3. Thorlabs' Full reflective mirror which reflects the beam without power loss. By turning knobs on the mirror holder, the mirror can be tilted up, down, right, and left to change the direction of the laser beam.

4. Thorlabs standard irises used to block the beam and focus it on the center of the irises. This method used to control the beam direction easily.

5. Full reflective mirror.

6. Thorlabs' Zero-Order Half-Wave Plates are built by combining two Multi-Order Crystalline Quartz Wave Plates to obtain an optical beam path length difference of $\lambda / 2$. By rotating, Half-Wave plate laser energy can be increased and decreased according to the required power for the experiment.

7. Thorlabs' polarizer with narrowband beam-splitting coatings deposited on the front surface of the plate. This optical device designed for various laser wavelengths such as $1064 \mathrm{~nm}$ and 532nm. Polarizer splits the beam into two components in the direction of the initial beam, and to the perpendicular direction. Beam dump can be used to block the perpendicular beam.

8. Use PowerMeter (Figure C2) to measure the power of the laser beam in continuous pulsed mode. 


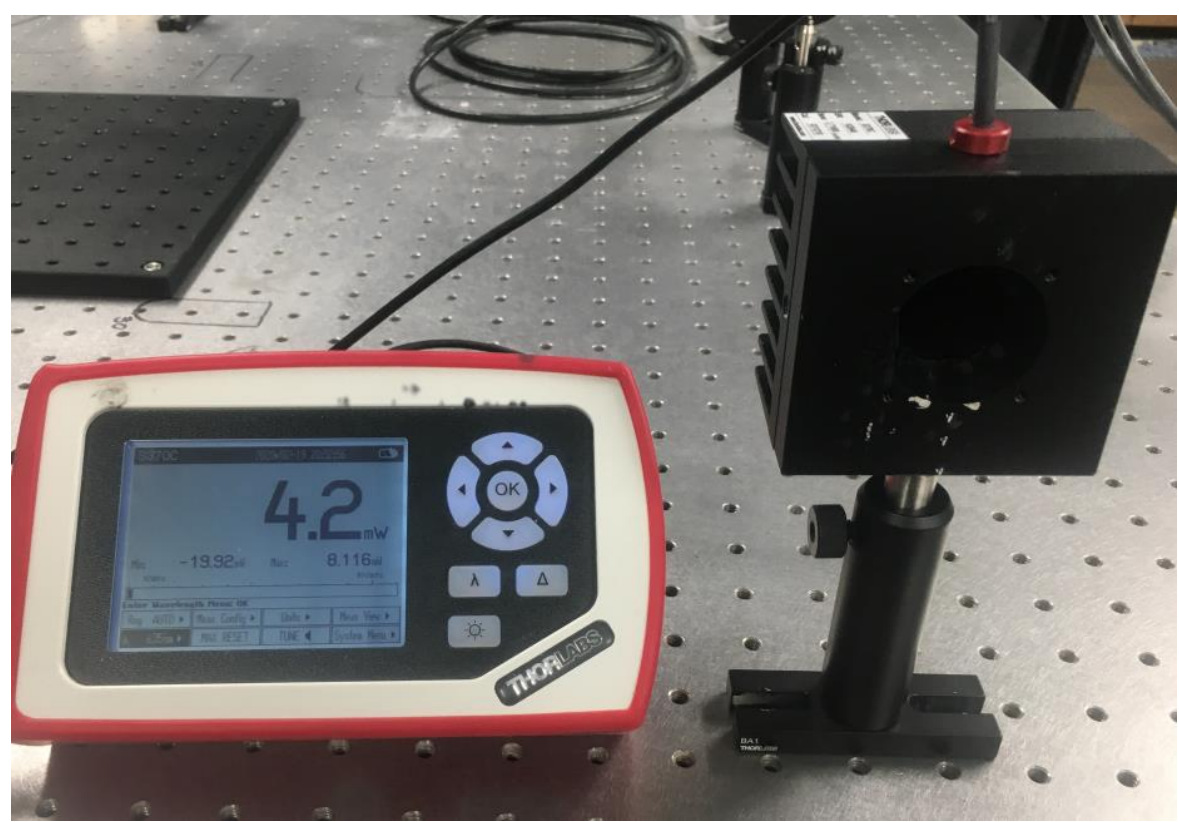

Figure C2. PowerMeter. 
Literature Cited:

1. V.A. Grazhulis, W.G. Schmidt, F. Bechstedt, and G.P. Srivastava, Adsorption of group-V elements on III-V ( $\left(\begin{array}{lll}1 & 1 & 0\end{array}\right)$ surfaces. Surface Science Reports 25, 141 (1996).

2. Y.-F. Zhang, J.-F. Jia, Z. Tang, T.-Z. Han, X.-C. Ma, and Q.-K. Xue, growth, stability and morphology evolution of $\mathrm{Pb}$ films on $\mathrm{Si}(111)$ prepared at low temperature. Surface Science 596(1), L331-L338 (2005).

3. M.M. Ozer, C.-Z. Wang, Z. Zhang, and H.H. Weitering, Quantum size effects in the growth, coarsening, and properties of ultra-thin metal films and related nanostructures. Journal of Low Temperature Physics 157, 221-251 (2009).

4. W.B. Su, C.S. Chang, and T.T. Tsong, Quantum size effect on ultra-thin metallic films. Journal of Physics D: Applied Physics 43, 013001 (2010).

5. M. Li, J.W. Evans, C.Z. Wang, M. Hupalo, M.C. Tringides, T.L. Chan, and K.M. $\mathrm{Ho}$, Strongly-driven coarsening of height-selected $\mathrm{Pb}$ islands on $\mathrm{Si}(111)$. Surface Science 601, L140-L144 (2007).

6. Y. Han and D.-J. Liu, Quantum size effects in metal nanofilms: Comparison of an electron-gas model and density functional theory calculations. Physical Review B 80, 155404 (2009).

7. J. Smedley, T. Rao, and J. Sekutowicz, Lead photocathodes. Physical Review Special Topics - Accelerators and Beams 11(1), 013502 (2008).

8. D. H. Dowell, I. Bazarov, B. Dunham, K. Harkay, C.H. Garcia, R. Legg, H. Padmore, T. Rao, J. Smedley, and W.Wan, Cathode R\&D for future light sources. Nuclear Instruments and Methods in Physics Research Section A: Accelerators, Spectrometers, Detectors and Associated Equipment 622(3), 685-697 (2010).

9. F. Gontad, A. Lorusso, G. Gatti, M. Ferrario, L. G. Passione, L.Persano, N. Lovergine, and A. Perrone, Characterization of photocatodes based on $\mathrm{Pb}$ thin film deposited by UV pulsed laser ablation. Journal of Materials Science and Technology 30, 37 (2014).

10. A. Lorusso, F. Gontad, E. Broitman, E. Chiadroni, and A. Perrone, Characterisation of $\mathrm{Pb}$ thin films prepared by the nanosecond pulsed laser deposition technique for photocathode application. Thin Solid Films 579, 50-56 (2015).

11. A. Lorusso, F. Gontad, A. Perrone, and N. Stankova, Highlights on photocathodes based on thin films prepared by pulsed laser deposition. Physical Review Special Topics - Accelerators and Beams 14, 090401 (2011).

12. A. Lorusso, F. Gontad, A. P. Caricato, E. Chiadroni, E. Broitman, and A. Perrone, Structural and morphological properties of metallic thin films grown by pulsed laser deposition for photocathode application. Applied Physics A 122, 162 (2016).

13. D. Velázquez, R. Seibert, H. Ganegoda, D. Olive, A. Rice, K. Logan, Z. Yusof, L. Spentzouris, and J. Terry, Tailoring the emissive properties of photocathodes through materials engineering: Ultra-thin multilayers. Applied Surface Science 360, 762 (2016). 
14. F. Gontad, A. Lorusso, A. Klini, A. Loufardaki, M. Panareo, C. Fotakis, and A. Perrone, Picosecond and subpicosecond pulsed laser deposition of $\mathrm{Pb}$ thin films. Physical Review Accelerators and Beams 16, 093401-6 (2013).

15. J. C. Miller, Laser Ablation: Principles and Applications. Springer, Berlin, 1994.

16. R. Eason, Pulsed laser deposition of thin film applications. John Wiley \& Sons, Inc., Hoboken, NJ 2007.

17. J. Schubert, M. Siegert, M. Fardmanesh, W. Zander, M. Prompers, C. Buchal, J. Lisoni, and C.H. Lei, Superconducting and electro-optical thin films prepared by pulsed laser deposition technique. Applied Surface Science 168(1-4), 208-214 (2000).

18. F. Gontad, A. Lorusso, A. Klini, A. Loufardaki, M. Panareo, C. Fotakis, and A. Perrone, Picosecond and subpicosecond pulsed laser deposition of $\mathrm{Pb}$ thin films. Physical Review Special Topics - Accelerators and Beams 16(9), 093401 (2013).

19. D. B. Chrisey and G. K. Hubler, Pulsed laser deposition of thin films. Wiley Inc, New York, NY 1994.

20. D. Dijkkamp and T. Venkatesan, Preparation of $\mathrm{Y}-\mathrm{Ba}-\mathrm{Cu}$ oxide superconductor thin films using pulsed laser evaporation from high Tc bulk material. Applied Physics Letters 51, 619 (1987).

21. P. Mele, K.M., T. Horide, O. Miura, A. Ichinose, M. Mukaida, Y. Yoshida, and S. Horii, Tuning of the critical current in $\mathrm{YBa}^{2} \mathrm{Cu} 3 \mathrm{O} 7-\mathrm{x}$ thin films by controlling the size and density of Y2 O3 nanoislands on annealed SrTiO3 substrates. Superconductor Science and Technology 19, 44-50 (2006).

22. P. Badica, K. Togano, S. Awaji, and K. Watanabe, Growth of superconducting MgB 2 films by pulsed-laser deposition using a Nd-YAG laser. Superconductor Science and Technology 19(2), 242 (2006).

23. A. Venimadhav, M.S. Hegde, R. Rawat, I. Das, and M. El Marssi, Enhancement of magnetoresistance in $\mathrm{La} 0.67 \mathrm{Ca} 0.33 \mathrm{MnO} 3 / \mathrm{Pr} 0.7 \mathrm{Ca} 0.3 \mathrm{MnO} 3$ epitaxial multilayers. Journal of Alloys and Compounds 326(1-2), 270-274 (2001).

24. A.O. Er, W. Ren, and H.E. Elsayed-Ali, Low temperature epitaxial growth of Ge quantum dot on $\mathrm{Si}(100)-(2 \times 1)$ by femtosecond laser excitation. Applied Physics Letters 98(1), 013108 (2011).

25. I.N. Mihailescu, V.S. Teodorescu, E. Gyorgy, A. Luches, A. Perron, and M. Martino, About the nature of particulates covering the surface of thin films obtained by reactive pulsed laser deposition. Journal of Physics D: Applied Physics 31, 2236-2240 (1998).

26. W.-O. Siew, W.-K. Lee, H.-Y. Wong, T.-K. Yong, S.-S. Yap, and T.-Y. Tou, Investigation of droplet formation in pulsed $\mathrm{Nd}$ :YAG laser deposition of metals and silicon. Applied Physics A 101, 627-632 (2010).

27. S. J. Barrington, T.B., D. P. Shepherd, and R. W. Eason, The effect of particulate density on performance of $\mathrm{Nd}: \mathrm{Gd} 3 \mathrm{Ga} 5 \mathrm{O} 12$ waveguide lasers grown by pulsed laser deposition. Opt. Comm. 185, 145- 152 (2000).

28. S. Fähler, M. Störmer, and H. U. Krebs, Origin and avoidance of droplets during laser ablation of metals. Appl. Surf. Sci. 109-110, 433-436 (1997). 
29. C.H. Hur, K.B. Han, K.A. Joen, and S.Y. Lee, Enhancement of the dielectric properties of $\mathrm{Pb}(\mathrm{La}, \mathrm{Ti}) \mathrm{O} 3$ thin films fabricated by pulsed laser deposition. Thin Solid Films 400(1-2), 169-171 (2001).

30. D.L. Price, V. Henner, M. Khenner, Morphologies, metastability and coarsening of quantum nanoislands on the surfaces of the annealed $\mathrm{Ag}(110)$ and $\mathrm{Pb}(111)$ thin films. Journal of Applied Physics 124, 174302 (2018).

31. Richard J. O'Haire, Growth by pulsed laser deposition and characterisation of Zinc Oxide thin films and nanostructures. Dublin City University, 2009.

32. Samuli K., Microstructure characterization of pulsed laser deposited metal oxide nanoparticles. University of Oulu,2015.

33. Alejandro O. G., Physical prosesses in pulsed laser deposition. Eth Zurich, 2016.

34. Krishna S. Handbook of the thin-film deposition processes and techniques. Williamandrew Publishing $2^{\text {nd }}$ edition, Santa Carla California, 2002.

35. Schneider C.W., Lippert T. Laser Ablation and Thin Film Deposition. In: Schaaf P. (eds) Laser Processing of Materials. Springer Series in Materials Science,Springer, Berlin, Heidelberg, 139,2010.

36. Guus R., Dave H.A. Real-time growth monitoring by high pressure RHEED during pulsed laser deposition. University of Twente, 2005. 